\title{
Baseline Postirradiation Examination of Fuel Rodlets from the AFC-2E Experiment*
}

Fuel Cycle Research \& Development Advanced Fuels Campaign

Jason M. Harp

*Note that this document is prepared from materials presented in INL/LTD-15-36358

Prepared for GenIV SFR-AF PMB

July 2017

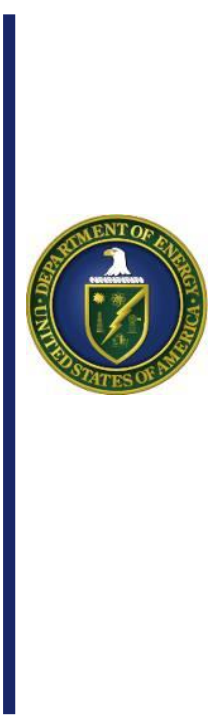




\section{DISCLAIMER}

Neither the U.S. Government nor any agency thereof, nor any of their employees, makes any warranty, expressed or implied, or assumes any legal liability or responsibility for the accuracy, completeness, or usefulness, of any information, apparatus, product, or process disclosed, or represents that its use would not infringe privately owned rights. References herein to any specific commercial product, process, or service by trade name, trade mark, manufacturer, or otherwise, does not necessarily constitute or imply its endorsement, recommendation, or favoring by the U.S. Government or any agency thereof. The views and opinions of authors expressed herein do not necessarily state or reflect those of the U.S. Government or any agency thereof. Being provided this document, directly or indirectly, shall not be construed to constitute a governmental export license or authorization. 
INL/MIS-17-42670

Revision 0

\title{
Baseline Postirradiation Examination of Fuel Rodlets from the AFC-2E, Experiment
}

\author{
Jason M. Harp \\ July, 2017 \\ Idaho National Laboratory \\ Idaho Falls, Idaho 83415
}

http://www.inl.gov

Prepared for

GenIV SFR-AF PMB 
INTENTIONALLY BLANK 


\section{CONTENTS}

Baseline Postirradiation Examination of Specific Fuel Rodlets from the AFC-2E, AFC-3A and

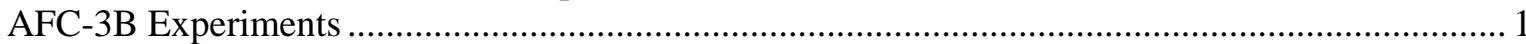

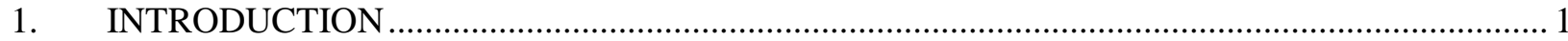

2. FABRICATION AND IRRADIATION HISTORY …....................................................... 1

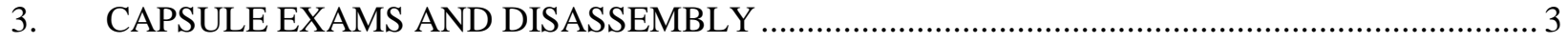

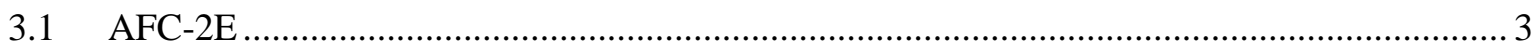

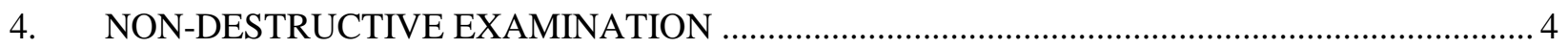

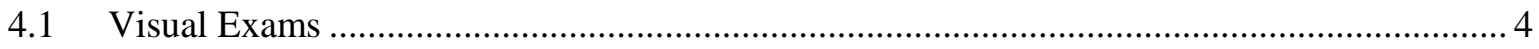

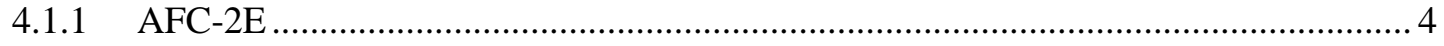

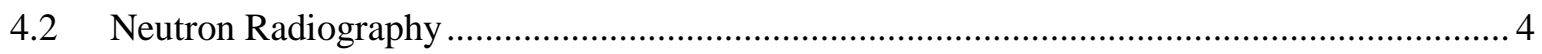

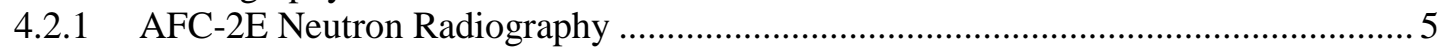

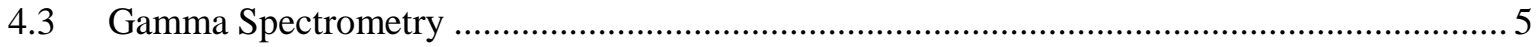

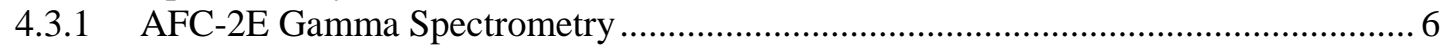

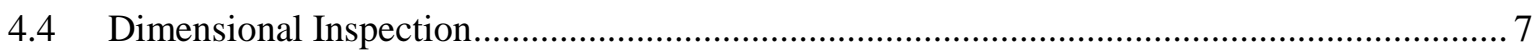

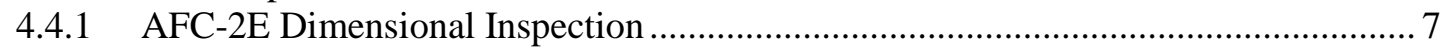

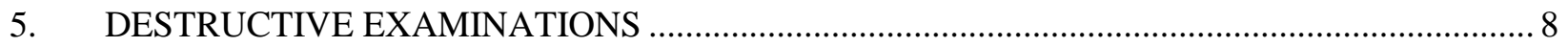

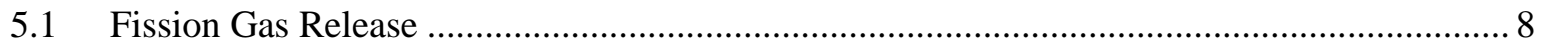

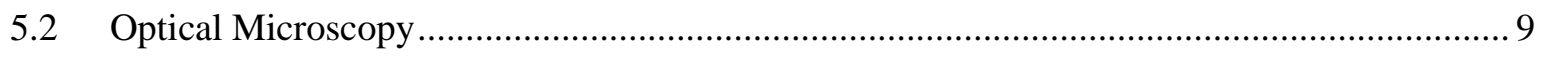

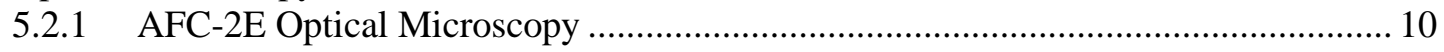

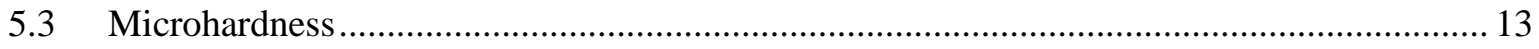

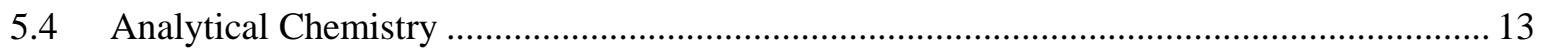

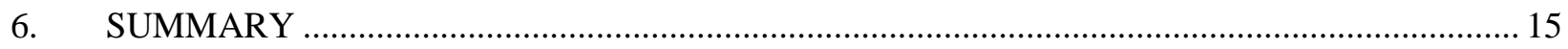

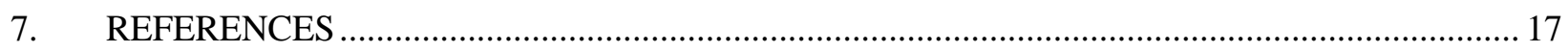

FIGURES

Figure 1. AFC-2 Cross section with capsule and rodlet. .......................................................................................

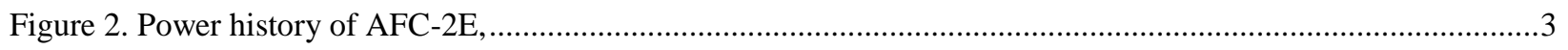

Figure 3. Disassembly of AFC-2E R6 from the AFC-2E capsule using clamshell technique.....................................

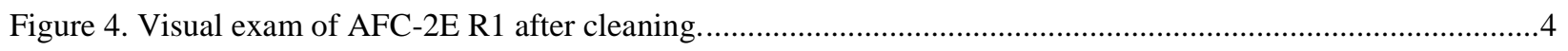

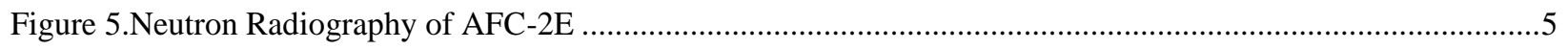

Figure 6. Gamma spectrometry of AFC-2E R2 with neutron radiography ..............................................................

Figure 7. Dimensional inspection of AFC-2E rodlets after cleaning.

Figure 8. AFC-2E Optical Microscopy (montage of images collected at 50X magnification) ..................................11 
Figure 9. (a) AFC-2A R3 with in-pile melting, (b) $\mathrm{U}-10 \mathrm{wt} \% \mathrm{Zr}$ fuel pin segment (3 at.\% BU) after being heated at $750^{\circ} \mathrm{C}$ for $1 \mathrm{~h},(\mathrm{c}) \mathrm{U}-10 \mathrm{wt} \% \mathrm{Zr}$ fuel pin segment ( 3 at. $\% \mathrm{BU}$ ) after being heated at $800^{\circ} \mathrm{C}$ for $1 \mathrm{~h}$

Figure 10. (a) AFC-2E R1, 200X, 13.32 at.\% burnup (b) EBR-II X-447A DP-70, X/L=0.49, 200X, 10 at\% burnup.

\section{TABLES}

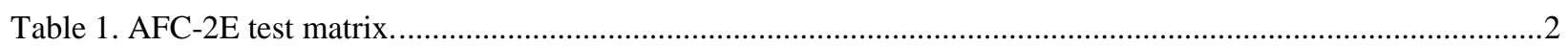

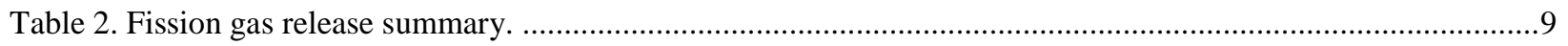

Table 3. Summary of microhardness testing from different rodlet cross sections. ..................................................13

Table 4. Burnup values for AFC-2E. ......................................................................................................... 


\section{Baseline Postirradiation Examination of Fuel Rodlets from the AFC-2E Experiments \\ 1. INTRODUCTION}

Baseline postirradiation exam (PIE) has been completed on four experiments from the Advanced Fuels Campaign (AFC) series of experiments. The AFC is a part of Fuel Cycle Research \& Development (FCRD) that seeks to develop and demonstrate the technologies needed to transmute long-lived transuranic actinide isotopes contained in spent nuclear fuel via fast reactor technology. As part of this development, candidate nuclear fuels and possible transuranic transmutation compositions undergo irradiation testing in a prototypic fast reactor spectrum. Postirradiation examination of these materials provides data on reactor fuel performance and input into future fuel design choices. ${ }^{1}$

The examined experiment was from the AFC- 2 series of experiments. ${ }^{2}$ The examined AFC-2E experiment is a continuation studying fast reactor and transmutation fuel begun by other AFC experiments. ${ }^{3,4}$ Key performance parameters are irradiation growth and swelling, He and fission gas release fractions, fission product and fuel constituent migration, and fuel cladding chemical interaction (FCCI). One of the AFC-2 experiments, AFC-2E, was expected to provide performance data on archived EBR-II ternary fuel (U-Pu-Zr) in comparison with newly cast ternary fuel and ternary fuel with minor actinides. It was expected that PIE results from AFC-2E could be compared with the large archive of fuel performance data collected during the operation of EBR-II; this would help identify performance differences between fuel irradiated in a true fast spectrum and fuel irradiated in the epithermal spectrum achieved in AFC irradiation through the use of cadmium baskets. Interpretation of all these experiments relies on a basic understanding of the prior history of fast reactor fuel performance, which has been summarized periodically in the literature. $5,6,7,8$

Experiments in the AFC series all undergo a standard set of PIE measurements. Visual exams of all capsules are followed by neutron radiography and gamma spectrometry. These exams are used to identify the experiments and provide a first look to determine if anything unexpected has occurred during irradiation. They also help guide disassembly of the capsules. After the capsules are disassembled, the rodlets are visually examined and undergo neutron radiography and gamma spectrometry in more detail than with the capsule scans. The rodlets are inspected for any change in their axial or radial dimensions. These non-destructive exams are performed on all rodlets; then rodlets go through various destructive exams, including: fission gas release and plenum volume analysis, metallography, microhardness testing, and chemical burnup analysis. These non-destructive and destructive exams are considered the "baseline" and will be reported here. Some additional non-destructive exams, namely gamma-ray tomography of select rodlets, have also been performed. If radiation levels are low enough, samples from optical metallography may be sent for further electron microscopic analysis and other advanced characterization techniques in the future.

This report focuses on the results from the different examinations performed in the Hot Fuel Examination Facility (HFEF) hot cell and other facilities. Descriptions of equipment used to collect the relevant data are provided as is necessary for interpretation of the data. A more detailed description of the equipment and the data collection methodology can be found in References 9 and 10.

\section{FABRICATION AND IRRADIATION HISTORY}

The AFC-2E irradiation test geometry, rodlet composition, and irradiation history are summarized in this section to provide clarity when interpreting the PIE results. The fabrication and pre-irradiation characterization of AFC-2E is documented in References 11 and 12, and the irradiation goals are outlined in Reference 13. The AFC-2 series was irradiated in the ATR East Flux Trap. Illustrations of the cross sections of the AFC-2 experiment is shown in Figure 1. Each AFC experiment consists of a fuel material (actinide alloy or compound) encapsulated in a sealed cladding material (HT-9 ferritic martensitic steel) 
and further encapsulated in a stainless steel capsule that serves as the primary boundary between the ATR primary coolant and the experiment. The power in the rodlets is driven by the power of the ATR, and the enrichment of the fuel material is tailored to give the programmatically desired linear heat generation rate at the expected ATR power conditions. The gas gap between the rodlet and the capsule is used to control the irradiation temperature in the rodlet, given some linear heat generation rate. The fuel material and the cladding material are referred to as the rodlet, and the stainless steel capsule is referred to as the capsule. When positioning the experiments in different ATR positions, the capsules are placed in baskets. The experiments utilized a Cd-shrouded basket to eliminate thermal neutrons, thus creating a neutron energy spectrum that is closer to a fast reactor spectrum than can normally be achieved in a thermal neutron reactor such as ATR. AFC-2 rodlets were encapsulated in a single capsule. It should be noted that Figure 1 does not include the Cd-shrouded basket.

The nominal composition of the AFC-2E rodlets is shown in Table 1. The actual compositions varied slightly and can be acquired from Reference 12 for AFC-2E. The slight variations in the metallic fuel away from the nominal composition are not expected to impact interpretation of the PIE results.

The as-run irradiation conditions of all the experiments are captured in as-run ECARs for each ATR cycle. AFC-2E was in ATR from Cycles 145A (9/5/2009) to 150B (11/26/2011). ${ }^{14-24}$ The power of the AFC-2 experiments was dominated by the East Flux Trap power, which is plotted in Figure 2. The time period each test was in the reactor and the hourly power history that drove the different experiments is all plotted in Figure 2.

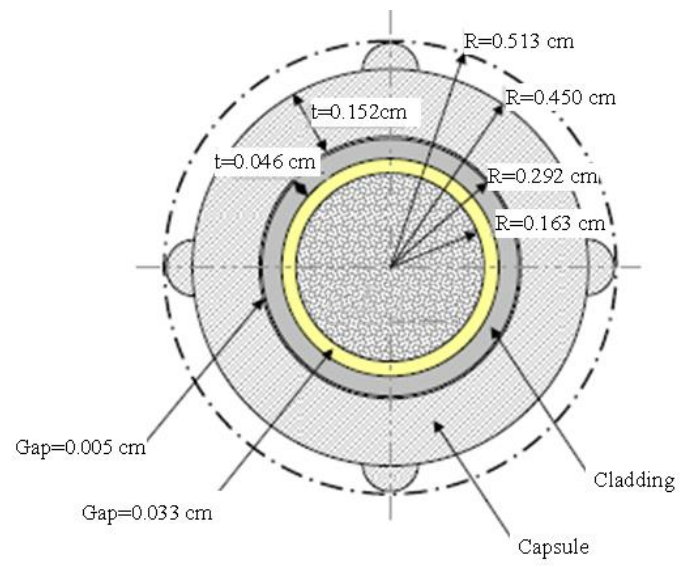

Figure 1. AFC-2 Cross section with capsule and rodlet.

Table 1. AFC-2E test matrix.

\begin{tabular}{ll}
\hline Rodlet ID & Nominal Composition \\
\hline AFC-2E R1 & U-20Pu-10Zr \\
AFC-2E R2 & U-20Pu-10Zr (EBR-II) \\
AFC-2E R3 & U-20Pu-3Am-2Np-10Zr \\
AFC-2E R4 & U-20Pu-10Zr \\
AFC-2E R5 & U-20Pu-3Am-2Np-10Zr \\
AFC-2E R6 & U-20Pu-10Zr (EBR-II) \\
\hline
\end{tabular}




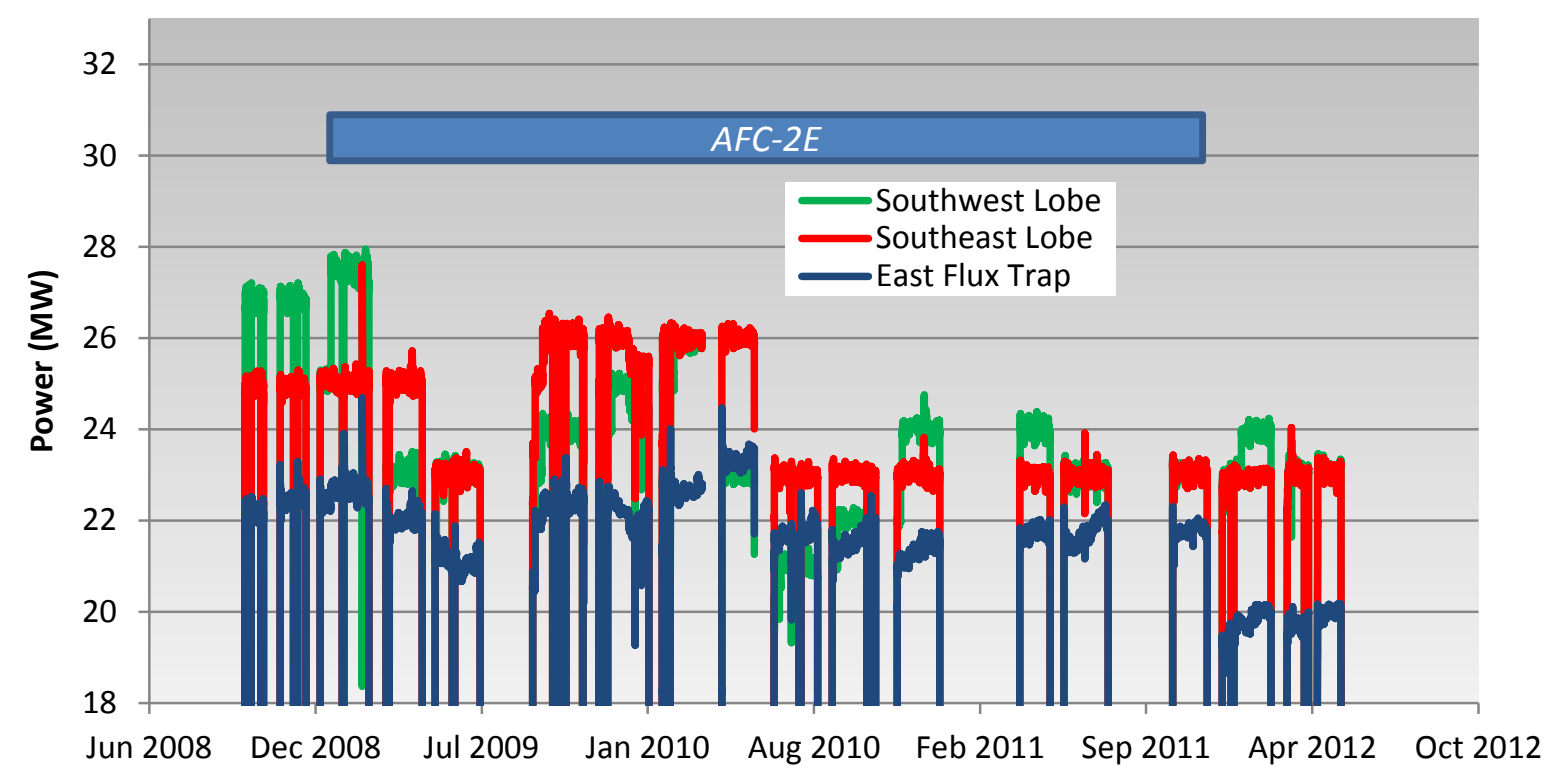

Figure 2. Power history of AFC-2E,

Numbers preceding an element indicate weight $\%$.

\section{CAPSULE EXAMS AND DISASSEMBLY}

Before rodlets are removed from their capsules, the capsules undergo a series of non-destructive exams (NDE) to verify nothing catastrophic has occurred during irradiation or shipment and to help identify the location of the rodlets in the capsule. Visual exams, neutron radiography, and gamma spectrometry are performed on all rodlets before disassembly.

\section{$3.1 \quad$ AFC-2E}

Visual exams, neutron radiography, and gamma spectrometry were performed on the AFC-2E rodlets before disassembly. Nothing remarkable was seen in the visual exam. The neutron radiography was used to guide the sectioning of the AFC-2E capsule. The capsule neutron radiography indicated that the integrity of some of the AFC-2E rodlets may have been compromised during irradiation. Disassembly proceeded with caution.

After sectioning the AFC-2E capsule, it was clear from the large amount of sodium present in the capsule that there were several failed rodlets in the experiment. Three rodlets were disassembled largely intact: R1, R2, and R6. Removal of R6 from the capsule is shown in Figure 3. The other three rodlets broke into two or three pieces and, in many cases, were bonded to the capsule wall with sodium. 


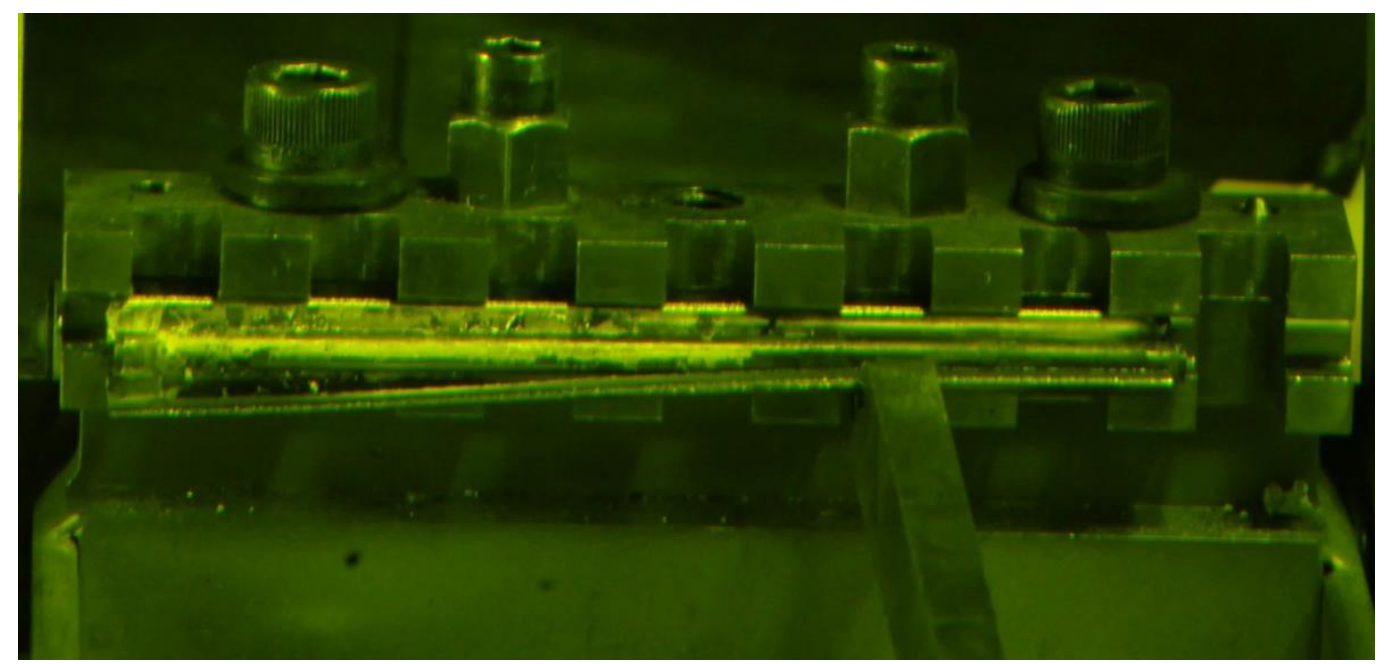

Figure 3. Disassembly of AFC-2E R6 from the AFC-2E capsule using clamshell technique.

\section{NON-DESTRUCTIVE EXAMINATION}

After the rodlets were removed from the capsules, they were run through the standard set of exams. This includes visual examination, neutron radiography, gamma spectrometry, and dimensional inspection.

\subsection{Visual Exams}

Visual exams are currently performed through window photography. The rodlets are placed on a neutral background fixture with a scale. The fixture is held in place by one of the in-cell electromechanical manipulators. At least two photographs of the rodlets are taken from different angles.

\subsubsection{AFC-2E}

After removal from the capsule, all the AFC-2E rodlets were covered in sodium residue from the failed rodlets. Rodlets 1, 2, and 6 did not have any visual cracks in the rodlet cladding. Rodlet 4 had a significant break in the rodlet wall. The initial visual exams for all the AFC-2E rodlets are in Appendix A. As in AFC-2D, all the cladding was discolored in the fueled region. Unlike AFC-2D, the sodium contamination prevented clear identification of the rodlets by their pre-irradiation markings. The intact rodlets were cleaned off with a small amount of ethanol and followed by gentle wiping. These rodlets were reexamined, and a puncture was found in AFC-2E R1. The additional visual exam photographs are also in Appendix A, and the puncture found in AFC-2E R1 is highlighted in Figure 4.

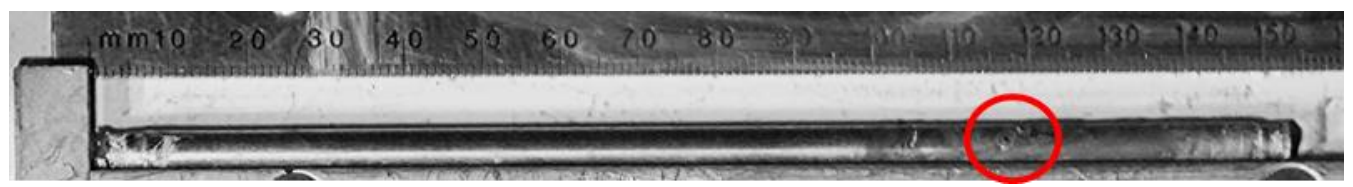

Figure 4. Visual exam of AFC-2E R1 after cleaning.

\subsection{Neutron Radiography}

Neutron radiography was performed with the HFEF NRAD reactor, which is a 250-kW TRIGA reactor located in the basement of HFEF. Items being radiographed are lowered down to the sub-cell area in a specimen positioning tube that penetrates the main hot cell floor. Neutrons pass through the specimen and expose different activation foils. The foils are used to expose film that is then developed to create radiographs. Cadmium filtered indium foils are used for epithermal neutron imaging, and 


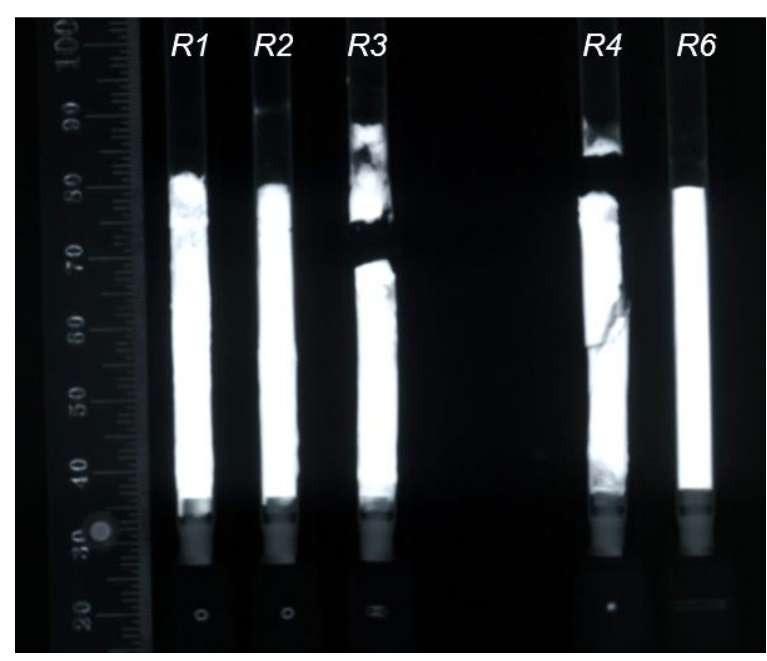

a) Thermal Neutron Radiography

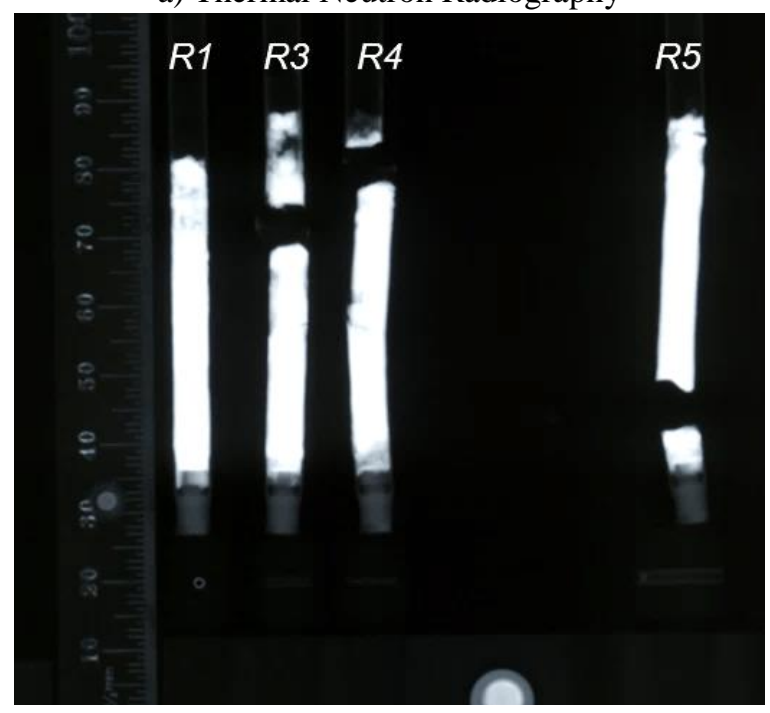

c) Thermal Neutron Radiography

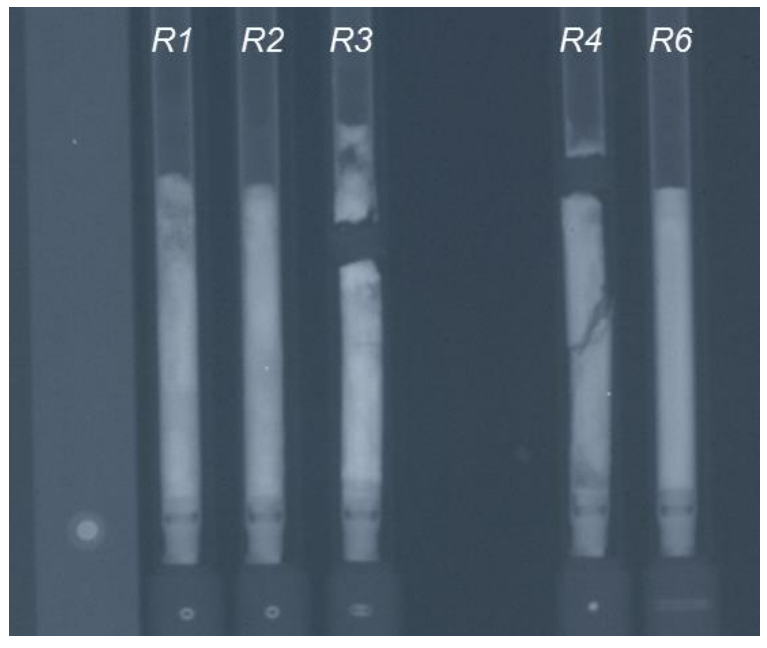

b) Epithermal Neutron Radiography

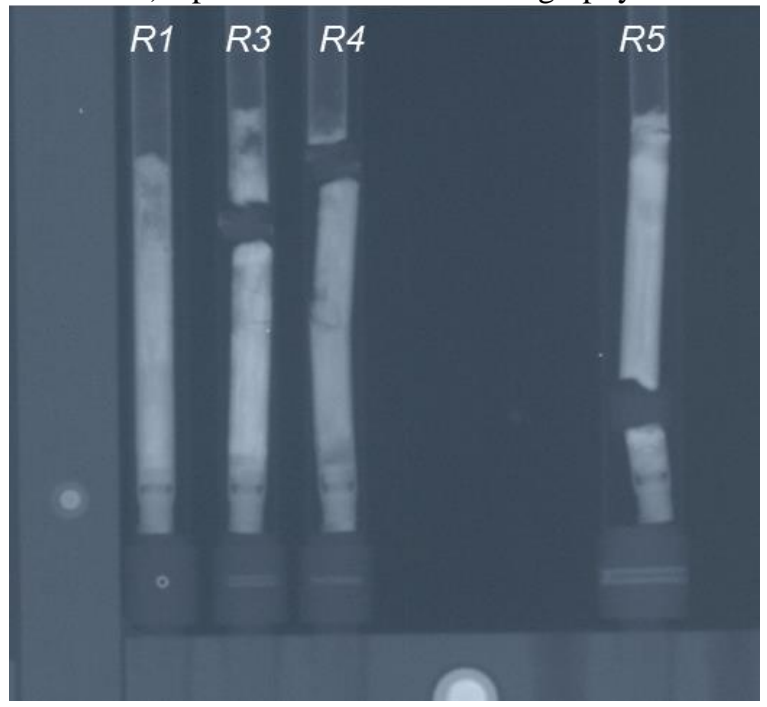

d) Epithermal Neutron Radiography

Figure 5.Neutron Radiography of AFC-2E

dysprosium foils are used for thermal neutron imaging. The radiography fixture contains a scale marked with $\mathrm{Gd}$ paint that produces a scale for quantitative measurements of fuel stack dimensional changes.

\subsubsection{AFC-2E Neutron Radiography}

The AFC-2E rodlets were shot in two different sets. Because of the extensive damage to the rodlets, they were repackaged in loose-fitting aluminum tubes and loaded into a NRAD fixture. The resulting radiographs are shown in Figure 5. In the second radiography R3 and R4 were turned $90^{\circ}$ to capture a different angle. The apparent presence of $U$ through the cladding in the thermal radiographs suggested significant FCCI, which was confirmed in optical microscopy. Cracks appeared near the fuel-sodium plug interface in the failed rodlets. This may be due to thermal stress in this region of enhanced FCCI from fission products moving to this region.

\subsection{Gamma Spectrometry}

Gamma spectrometry of all of the rodlets was performed using the HFEF Precision Gamma Scanner (PGS). The PGS has three major components: collimator, stage, and detector. The collimator penetrates the HFEF cell wall with a rectangular aperture that is adjustable form $0.254 \mathrm{~cm}$ to $0.00254 \mathrm{~cm}$ in height 
and is $2.2225 \mathrm{~cm}$ wide. The collimator can be rotated from a horizontal to vertical orientation. The stage manipulates the sample in front of the collimator in the plane facing the collimator and can rotate the sample about its central axis. The detector consists of a Compton suppressed High Purity Germanium (HPGe) detector, and its control system moves the stage and collimator and initiates scans.

\subsubsection{AFC-2E Gamma Spectrometry}

The AFC-2E experiment was scanned axially in $0.127 \mathrm{~cm}$ steps with the collimator set to 0.127 . Each scan had a live time of 5 minutes. The rodlets were examined by gamma spectrometry in the same $\mathrm{Al}$ containers that were used for neutron radiography. The thin-walled Al containers did not significantly impact the gamma ray signal. There were eight fission products that were strongly detected in the gamma spectrometry (Ru-106, Sb-125, Cs-134, Cs-137, Eu-154, Ce-144, Zr-95, and Nb-95), and two activation products (Co-60 and Mn-54). An example of gamma spectrometry from AFC-2E is shown in Figure 6, and the abbreviated collection for this report is in Appendix B. Gaps in the gamma spectrometry data of the failed rodlets are due to the Al spacers between rodlet pieces. Neutron radiography for each rodlet is included to aid interpretation. In metallic fuel, Cs fission products will dissolve in the sodium, transport up to the top of the fuel, and remain in the Na plug that forms above the fuel. The Na plug is faintly visible in the radiograph included in Figure 6; its top is denoted by a faint line above the fuel. The presence or absence of a Cs spike in the Na plug is an important indicator of rodlet integrity. If a rodlet fails, it will lose its Na and distinctive Cs spike. While 2E R2 has the most distinctive spike, 2E 2E R6 also has Cs spikes in the Na plug. The failed rodlets do not have Cs in the plenum. A spike of Eu-154 is observed above the Na plug in Figure 6 and gamma spectrometry from other rodlets. This has not been previously reported in other PIE of metallic fast reactor fuel. The Eu behavior is distinctly different from the behavior of $\mathrm{Ce}$, which is also a lanthanide. The Ce tends to stay in the fuel. This difference in lanthanide behavior is likely due to differences in the thermodynamic stability of the two elements in uranium. Understanding whether this Eu behavior is due to the unusual temperatures achieved in AFC$2 \mathrm{E}$ or if it is a previously unobserved phenomenon merits further study. The Co-60 in Figure 6 indicates the location of cladding and end plugs in the rodlet. 


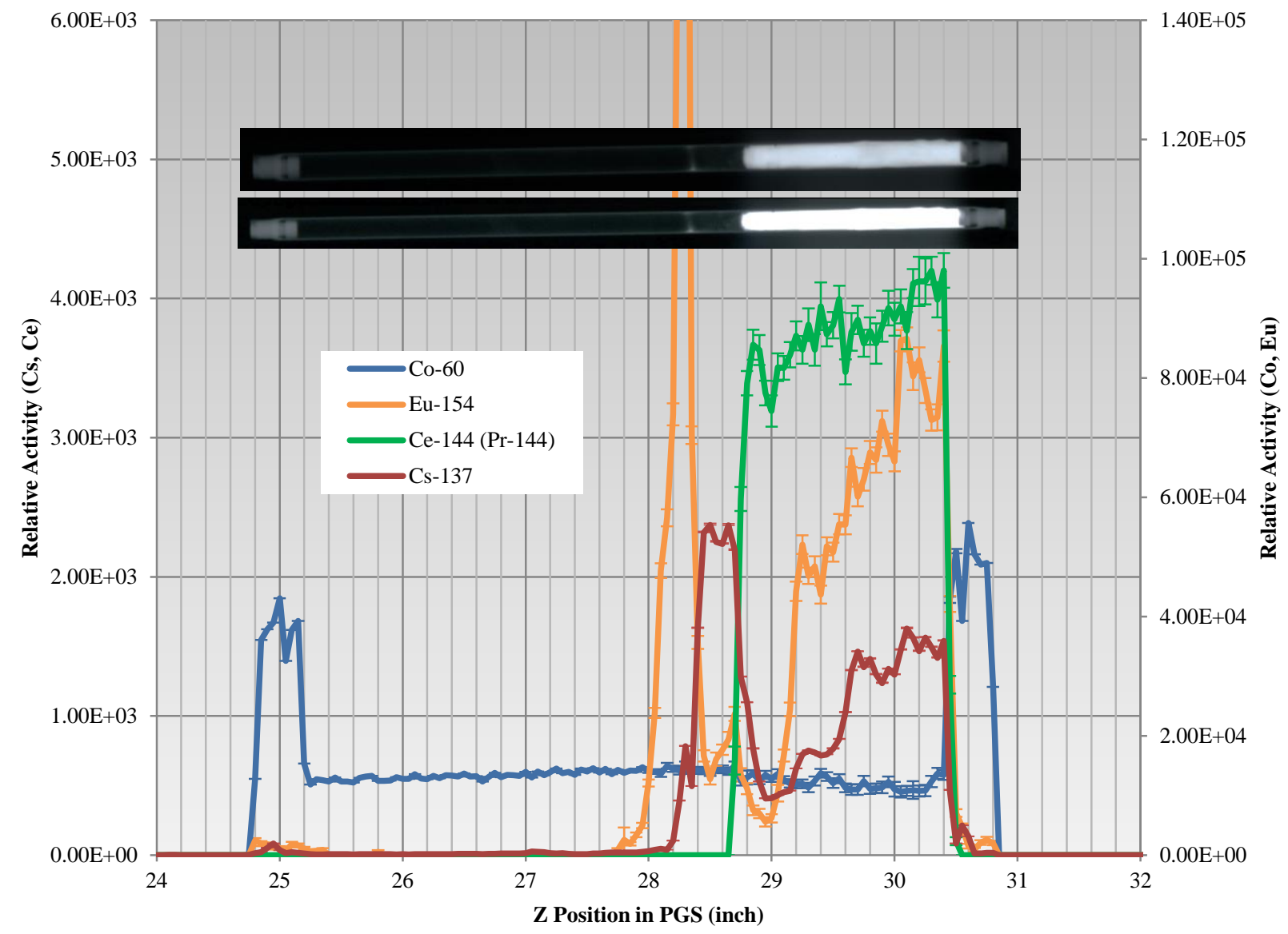

Figure 6. Gamma spectrometry of AFC-2E R2 with neutron radiography.

\subsection{Dimensional Inspection}

Dimensional inspection of the rodlets was performed with the HFEF plate and rodlet checker. This system uses contact sensors to determine the diameter of a rodlet at a specific axial location. The instrument also collects several diameter measurements at a single axial location for a specified number of angles. Rodlets were examined every $0.127 \mathrm{~cm}\left(0.050\right.$ in.) at five angles $45^{\circ}$ apart (the fifth angular measurement should have matched the first and was used to confirm measurements). The accuracy of the diameter measurements are $\pm 0.0005 \mathrm{~cm}(0.002$ in.). Often a diameter trace will contain a single point spike that is caused by small amounts of dust or other contaminants on the rodlet surface. Deformation of the rodlet that makes the cladding an oval shape will also appear in the measurements, but diameter growth in one angle will be matched by diameter shrinkage in other angles. Because of these anomalies, definite trends in diameter change are needed before a rodlet is considered to have actually deformed due to irradiation.

\subsubsection{AFC-2E Dimensional Inspection}

Three of the AFC-2E rodlets were inspected for dimensional changes. The plenum region was examined every $0.127 \mathrm{~cm}$, and the fuel region was examined every $0.0635 \mathrm{~cm}$ at four angles. The sodium on AFC-2E Rodlets 1, 2, and 6 from the other failed rodlets was cleaned off using ethanol and gentle wiping with manipulators and paper towels. The change in diameter was converted to diametral strain and averaged over the first four collection angles. The results of this inspection are shown in Figure 7. Some of the strain shown may be due to residual sodium on the rodlet surface, but the exhibited strain is fairly consistent between the measured angles and is likely true deformation of the cladding. When 
considered with the optical microscopy of these rodlets (Section 5.2.1), the localized deformation seen in the fuel region of Rodlet 2 may indicate regions of significant FCCI that have weakened the cladding, allowing cladding deformation.

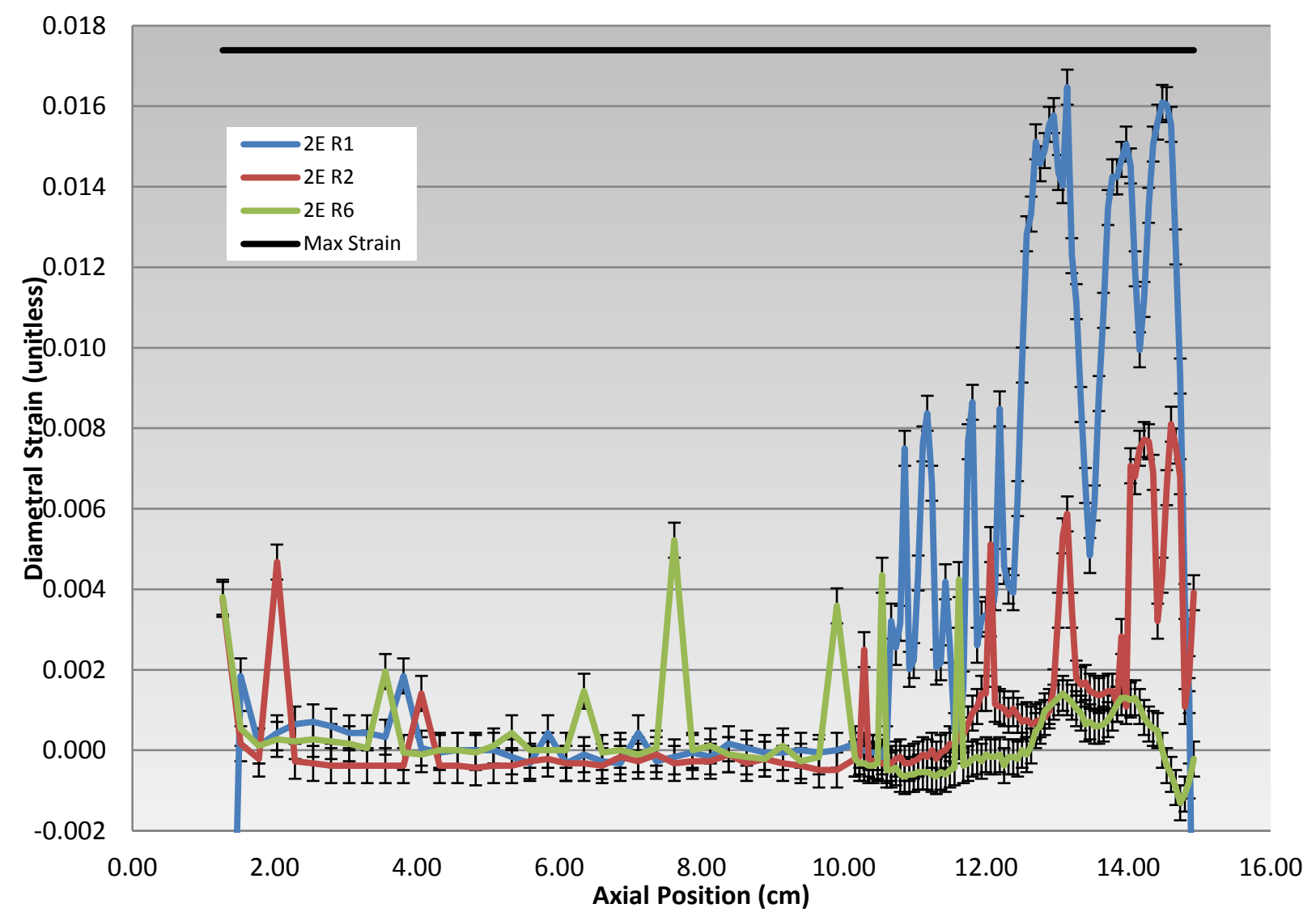

Figure 7. Dimensional inspection of AFC-2E rodlets after cleaning.

\section{DESTRUCTIVE EXAMINATIONS}

Destructive exams were performed on all AFC-2E rodlets. Destructive examination is considered to start when the fuel pins are punctured for fission gas release analysis. Baseline destructive exams include fission gas release analysis, optical microscopy, microhardness testing, and analytical chemistry analysis for burnup.

\subsection{Fission Gas Release}

Fission gases were collected from the rodlets using the HFEF Gas Assay, Sample, and Recharge (GASR) system. Rodlets were punctured using a $150 \mathrm{~W}$ Nd-YAG laser system, and a gas sample was collected in a stainless steel bottle external to the hot cell. Void volume in the rodlet was then determined by a series of backfills into the punctured rodlet and expansions into the GASR system. The fuel rodlet internal gas pressure was derived from the void volume measurement and the initial gas pressure measurement upon puncture. Fission gas analysis was performed by gas mass spectrometry. Results of fission gas analysis provided total elemental composition and krypton and xenon isotopic composition. A summary of results is shown in Table 2. The combined $\mathrm{Kr}$ and $\mathrm{Xe}$ release is based on an estimate of the number of fissions that occurred in each rodlet from U-235 and Pu-239 and an empirical relationship between fission and atoms of $\mathrm{Xe}$ and $\mathrm{Kr}$ produced. The number of fissions in each rodlet was determined from ICP-MS. This is discussed in Section 5.4 along with some geometric scaling factors to scale from 
the chemistry sample size to the entire rodlet. The ratio of fission from U-235 to Pu-239 was estimated from the $\mathrm{Kr}$ to $\mathrm{Xe}$ ratio present in the gas samples. For the Pu-bearing AFC-2 samples, $33 \%$ of fission was estimated to come from Pu-239, and for the AFC-3 samples, all fission was assumed to come from $\mathrm{U}-235$, which is reasonable for these low burnup rodlets. The production of $\mathrm{Kr}$ and $\mathrm{Xe}$ is based on the fast fission yields of the stable $\mathrm{Kr}$ and $\mathrm{Xe}$ isotopes.

Only three AFC-2E pins (R1, R2, and R6) were evaluated on GASR. The damage on the other pins was considered too severe to attempt a measurement on the plenum with the hope that fission gas was trapped above the Na plug. Rodlet 1 was found to be breached and was mostly filled with an air ( $\mathrm{N}$ and $\mathrm{O})$ or Ar mixture. The other two rodlets were successfully tested on GASR. Fission gas release from $2 \mathrm{E}$ $\mathrm{R} 2$ and $\mathrm{R} 6$ is reasonable.

The small volumes present in the AFC rodlets pose challenges for accurate pressure and volume measurements and calculations; small instrument uncertainties have a large effect on the calculated values (plenum pressure and volume). The pressure gauges in GASR are most accurate at full scale near 25 psi; however, initial puncture pressures for AFC rodlets were between 1 and 3 psi. Uncertainty in the as-built pressures and temperatures during fabrication also adds to uncertainty when calculating release fractions. Quantification of the uncertainties in the GASR system is an ongoing process that is being actively researched. Currently, repetition of the free volume determination measurement is used to produce a sample of measurements with a standard deviation between 1 and $2 \%$. However, there may still be biases in the free volume determination that cannot be measured by repetition. Additionally, the initial puncture pressure for the AFC rodlets is not better than $1 \%$ accurate, based on the stated uncertainty of the gauge by the manufacturer. Uncertainty in the initial puncture pressure and free volume determination combines to at least a 5\% uncertainty on the calculated plenum pressure. Recent efforts have been made to better characterize GASR response for larger fuel pins and higher plenum pressures by testing a set of well-characterized standards. The results of this effort show GASR can produce reliable, repeatable results. In the future, a similar set of tests will be performed to better characterize the response of GASR to standards that represent the pressures and volumes seen in AFC rodlets.

Table 2. Fission gas release summary.

\begin{tabular}{|c|c|c|c|c|c|c|c|c|c|}
\hline \multirow{2}{*}{ Rodlet } & \multirow{2}{*}{$\begin{array}{l}\text { Plenum } \\
\text { Pressure } \\
\text { (psi) }\end{array}$} & \multirow{2}{*}{$\begin{array}{l}\text { Plenum } \\
\text { Volume } \\
\left(\mathrm{cm}^{3}\right)\end{array}$} & \multicolumn{6}{|c|}{ Gas Composition - Major Components (\%) } & \multirow{2}{*}{$\begin{array}{l}\mathrm{Kr}+\mathrm{Xe} \\
\text { Gas } \\
\text { Release } \\
(\%)\end{array}$} \\
\hline & & & $\mathrm{He}$ & $\mathrm{N}$ & $\mathrm{O}$ & Ar & $\mathrm{Kr}$ & $\mathrm{Xe}$ & \\
\hline AFC-2E R1 & & & & 55.608 & 14.102 & 30.237 & & & \\
\hline AFC-2E R2 & 74.8 & 1.559 & 7.638 & 0.676 & 0.004 & 8.755 & 9.468 & 71.688 & $25.34 \%$ \\
\hline AFC-2E R6 & 107.0 & 1.503 & 6.270 & 0.113 & 0.013 & 7.871 & 9.923 & 73.551 & $43.66 \%$ \\
\hline
\end{tabular}

\subsection{Optical Microscopy}

Optical microscopy was performed on fuel cross sections to investigate irradiation-induced features in the fuel microstructure. Neutron radiography and the visual exams were used to guide the sectioning of the fuel in the approximate center of the fuel column. Grinding was achieved using 400 grit grinding plates followed by 800 and 1,200 grit plates. Polishing was achieved using 6, 3, 1, and $0.25 \mu \mathrm{m}$ diamond suspension. This produces a surface that is more than satisfactory for optical microscopy. Grinding and polishing were performed in the HFEF Containment Box (Window 2M). After polishing samples were transferred to the HFEF Met Box (Ar atmosphere) for examination on a Leitz MM5RT metallograph. Images were recorded with an integrated digital camera. Montages of the fuel cross sections were assembled from 50x images. Montages of scans across fuel cross sections were captured at both $100 \times$ and 200x. The light source was polarized during image collection, and images were captured in 8-bit color. Higher magnification images of features of interest were recorded. 
A few important historic fuel performance criteria are worth noting when interpreting the observed microstructure. Historically, $75 \%$ smeared density was found to be the optimum compromise between fuel loading and fuel swelling in metallic fast reactors. Obviously, fuel loading should be maximized to maximize cycle length or actinide destruction in a fast reactor. At $75 \%$ smeared density, as metallic fuel swells with fission gas production, the porosity will interconnect releasing fission gas to the plenum without placing excessive strain on the cladding. However, at high burnup, solid fission products begin to fill the voids and again begin to put strain on the cladding. Lower smeared density fuels are then necessary to push fuel performance to high burnup beyond 15 at.\% (\%FIMA). Alloying elements added to $U$ serve two purposes: to raise the melting temperature and to help stabilize the cubic phase of $U(\gamma U)$ or $\mathrm{U}$ and $\mathrm{Pu}$. Zirconium at $10 \mathrm{wt} . \%$ of the fuel historically worked very well for this purpose, but it does undergo constituent redistribution during irradiation. In $\mathrm{U}-10 \mathrm{Zr}$, the $\mathrm{Zr}$ migrates to the center of the fuel pin. This raises the melting temperature in the center of the pin where the temperature is hottest during steady state irradiation; however, this phenomenon lowers the melting temperature in the fuel periphery, which may be problematic in certain transient accidents. In ternary fuels with $\mathrm{U}-\mathrm{Pu}-10 \mathrm{Zr}$, the $\mathrm{Zr}$ concentrates in both the center of the fuel pin and at the pin periphery. In both cases, the $U$ depletes when the $\mathrm{Zr}$ concentrates, but Pu concentrations do not vary in ternary fuels under irradiation. Molybdenum serves the same purpose as $\mathrm{Zr}$ but does not undergo constituent redistribution. However, U-Mo alloys have much worse FCCI behavior than U-Zr alloys. Metallic interdiffusion drives FCCI in metallic fuels; however, the rate of interaction varies widely based on the interplay of all the major alloying elements present in the system and some of the minor constituents as well. Early work showed Ni-accelerated interdiffusion, which is one of the drivers to move from 300 series stainless steels to ferritic-martensitic steels. The presence of lanthanide fission products, either from high burnup or carryover from fuel reprocessing, can enhance FCCI. Historically, the addition of $\mathrm{Zr}$ to the $\mathrm{U}$ fuel was important in impeding FCCI. The eutectic temperature of $\mathrm{U}$ and $\mathrm{Fe}$ at $719^{\circ} \mathrm{C}$ is one important mechanism in metallic fuel FCCI, but other elements present at the fuel cladding interface impact the thermodynamics and kinetics of this eutectic point. Other elements, such as the rare earths in U-Zr alloy fuels, may also have low-temperature eutectic reactions that are equally important to the rate of interdiffusion driving FCCI. ${ }^{5,8}$

\subsubsection{AFC-2E Optical Microscopy}

With the significant cladding failures seen in AFC-2E, it was obvious from disassembly that the experiment had operated hotter than expected. The 50X montage images for AFC-2E are shown in Figure 8. Images were stitched together and blended using Adobe Photoshop CC using standard options. The optical microscopy from AFC-2E reveals extensive FCCI to the point where almost full wastage of the cladding has occurred in some of the observed cross sections. The cross sections from AFC-2E R1 and AFC-2E R6 represent the best irradiation performance and are comparable to some historic data as will be discussed subsequently. Overall the observable microstructure of AFC-2E is similar to earlier AFC-2 metallic fuel tests. Although there is less large circular porosity that is representative of fuel melting in AFC-2E than in similar cross sections from AFC-2A [30] and AFC-2B[31]. Only AFC-2E R5 (Figure 8e) shows the distinct large pore structure of melted fuel in its most central region. It should be noted that AFC-2E R2 and R6 were successfully punctured with GASR, fission gas was collected and back fills and expansions were possible. The split seen in the left side of Figure 8b likely occurred during sectioning. The split seen in Figure $8 \mathrm{a}$ on the lower right side also likely occurred during sectioning, but the hole observed in $2 \mathrm{E}$ R1 during visual exams is likely similar to the full through cladding FCCI event seen in Figure 8a. 


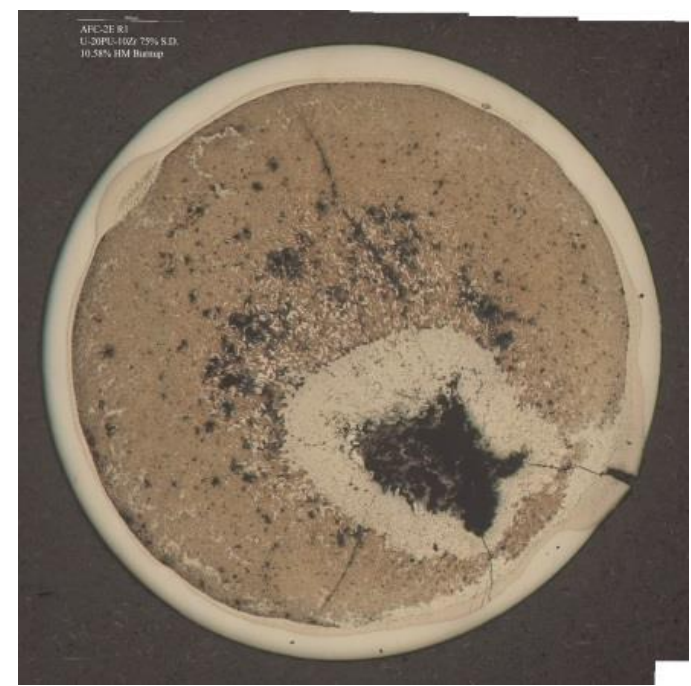

a) 2ER1 (MNT 13X)

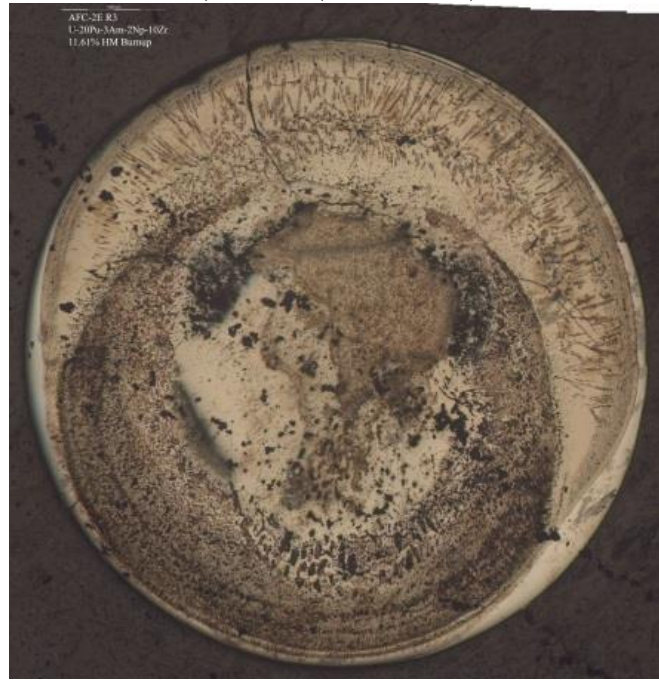

c) 2ER3 (MNT 15X)

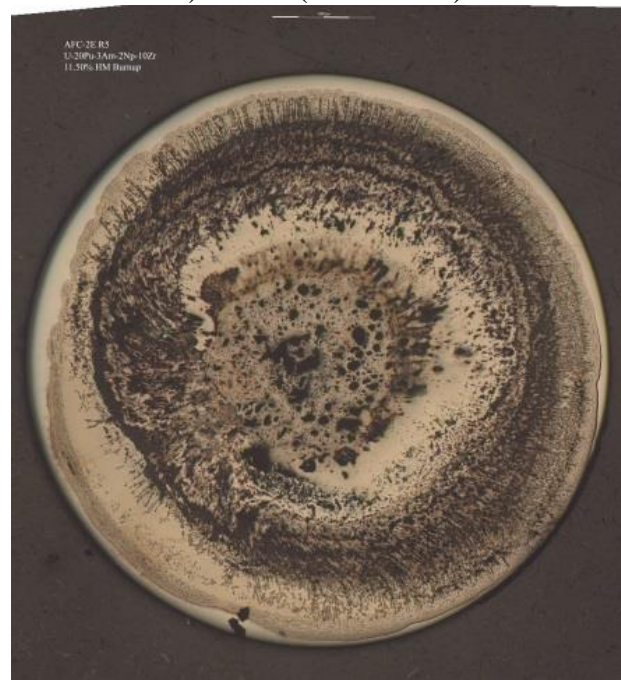

c) 2ER5 (MNT 17X)

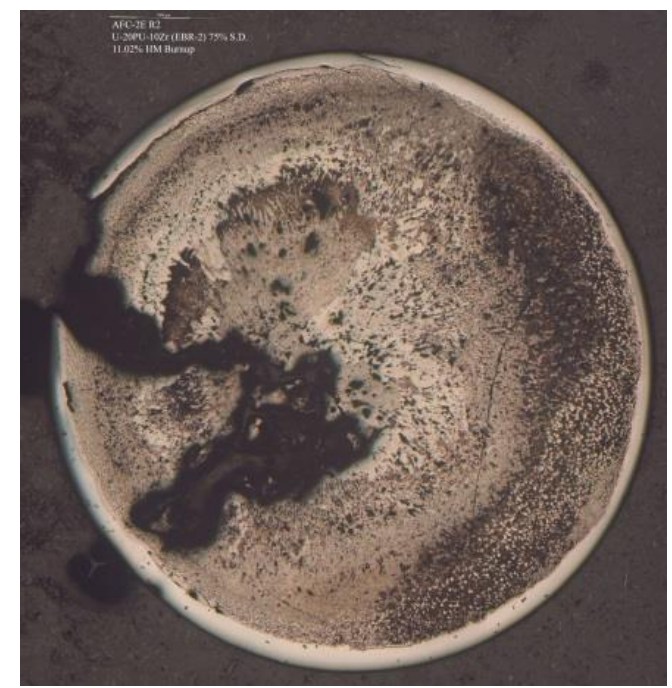

b) 2DR2 (MNT 14X)

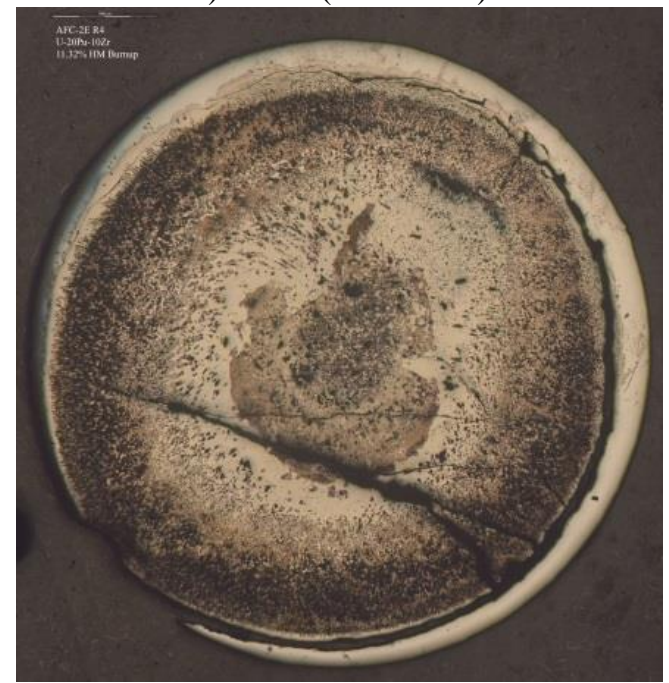

d) 2ER4 (MNT 16X)

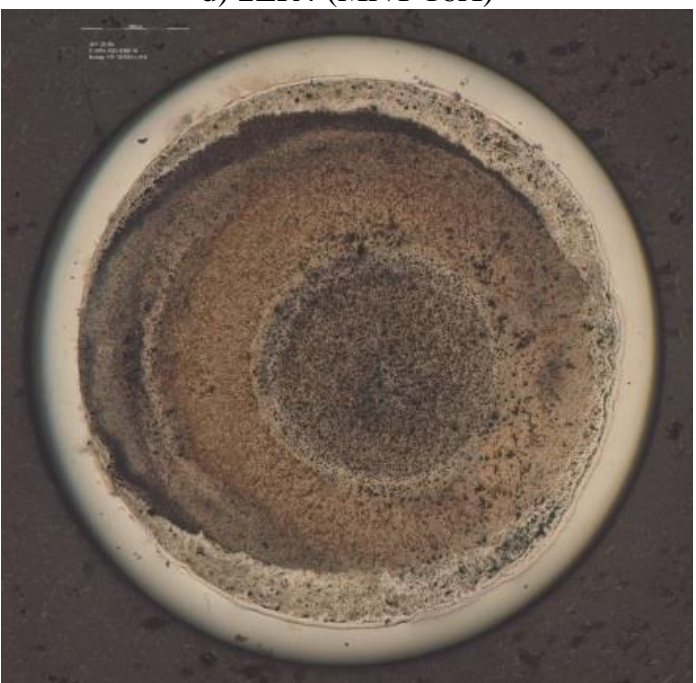

d) 2ER6 (MNT 18X)

Figure 8. AFC-2E Optical Microscopy (montage of images collected at 50X magnification) 
With the exception of possibly AFC-2E R5, the fuel in AFC-2E likely did not melt. A good example of fuel melting in-pile is shown in Figure 9(a) [30], and fuel melting in furnace tests is shown in Figure 9(b) and Figure 9(c) [32]. The foam structure in all these images with the large circular porosity typifies fuel melting. The lack of this "foam" structure suggests that the cladding temperature was less than $750^{\circ} \mathrm{C}$ which is the onset of melting in historic furnace

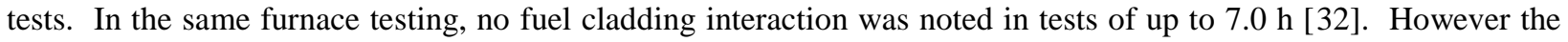
FCCI seen in AFC-2E suggests that the cladding temperature was greater than $650^{\circ} \mathrm{C}$. Fortunately, a set of pins irradiated in EBR-II (assembly X-447A) were intentionally tested at margin conditions. In the X-447A tests, the fuelcladding interface at beginning of life was $660^{\circ} \mathrm{C}[33,34]$. The similarity between the X-447A tests and the AFC-2E tests is illustrated in Figure 10. Two diameter scans across AFC-2E R1 (Figure 10a) and X-447A DP70 (Figure 10b) are directly compared. The radial variation in the fuel microstructure is striking, suggesting these two pins, which have very similar burnup, were irradiated under very similar conditions.

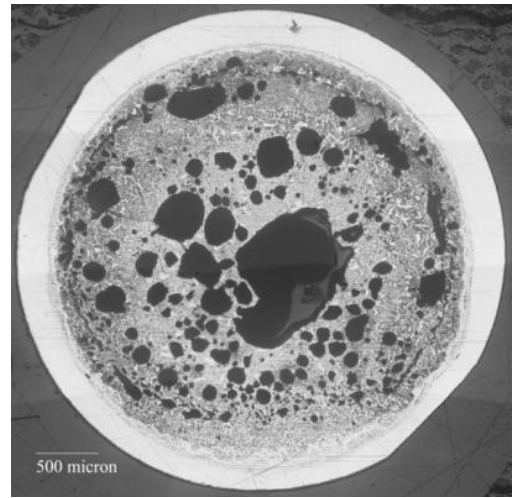

(a)

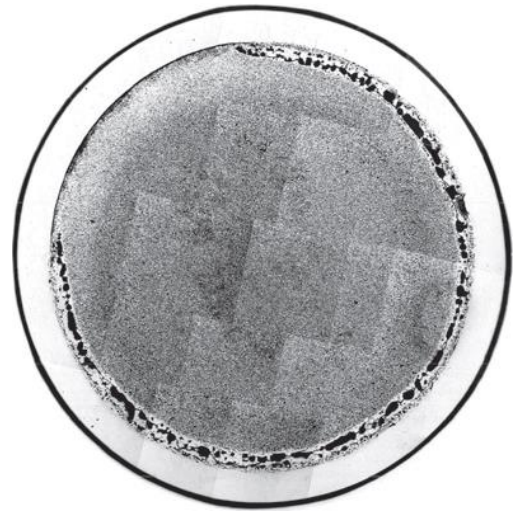

(b)

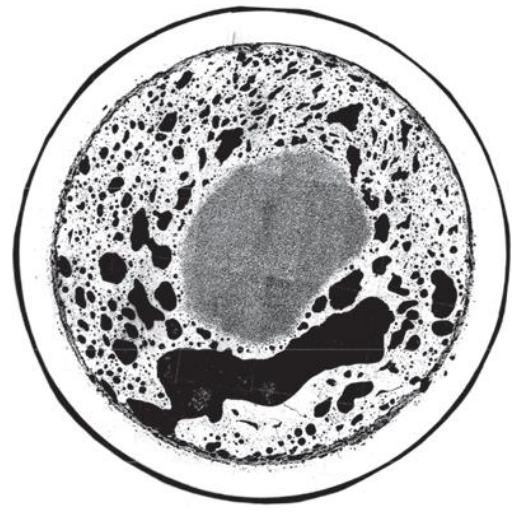

(c)

Figure 9. (a) AFC-2A R3 with in-pile melting, (b) U-10wt\% $\mathrm{Zr}$ fuel pin segment ( 3 at.\% BU) after being heated at $750^{\circ} \mathrm{C}$ for $1 \mathrm{~h}$, (c) $\mathrm{U}-10 \mathrm{wt} \% \mathrm{Zr}$ fuel pin segment ( 3 at.\% BU) after being heated at $800^{\circ} \mathrm{C}$ for $1 \mathrm{~h}$
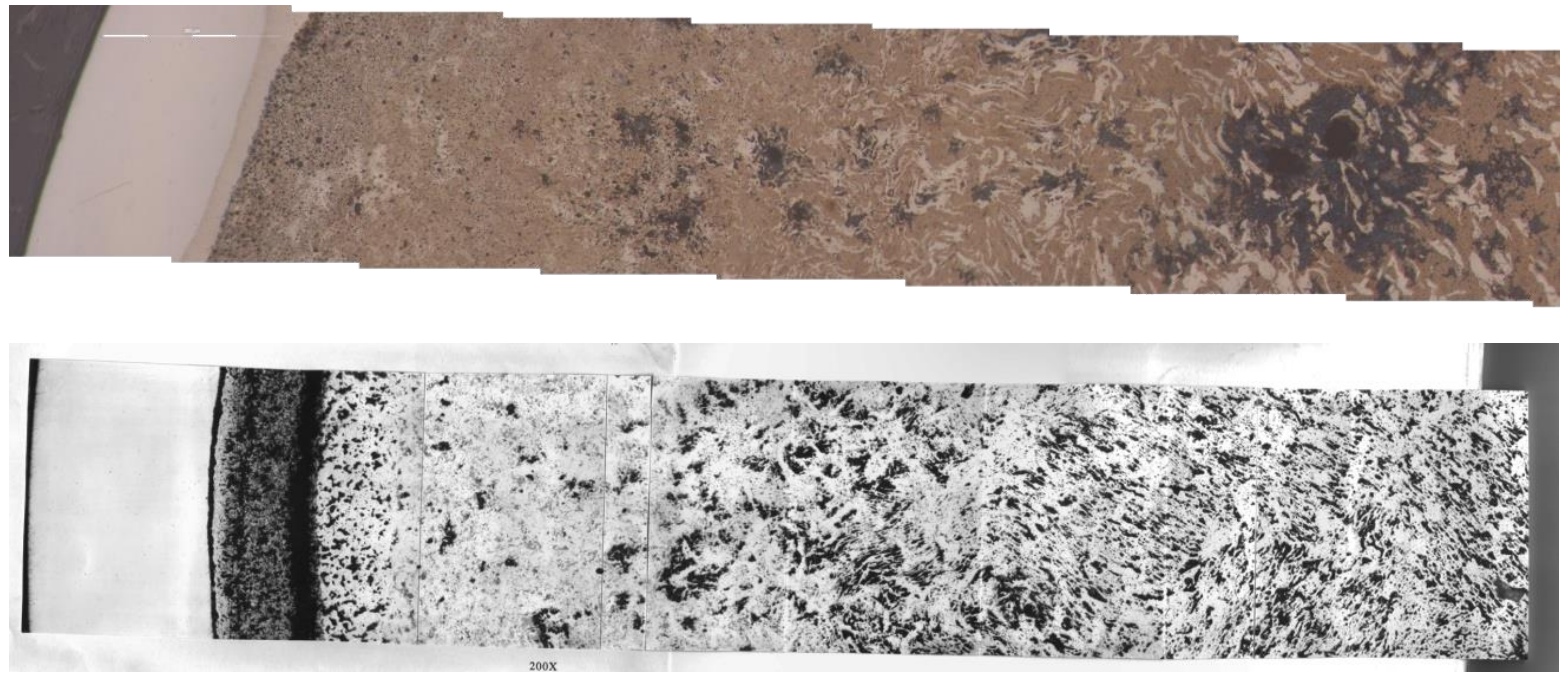

(b)

Figure 10. (a) AFC-2E R1, 200X, 13.32 at.\% burnup (b) EBR-II X-447A DP-70, X/L=0.49, 200X, 10 at\% burnup 


\subsection{Microhardness}

Microhardness testing was performed on the fuel met mounts using a LECO AMH43 microindentation hardness testing system installed in a shielded inert atmosphere alpha containment hot cell. Room temperature microhardness tests using a Vickers diamond pyramid were performed with a nominal load of $500 \mathrm{~g}$. The primary intent of microhardness testing is to identify changes in cladding mechanical properties that may be due to interaction between fuel and cladding. Decreases in cladding hardness (softening) may indicate cladding decarburization. Increases in cladding hardness (hardening) indicate FCCI between rare earth elements and the cladding.

Microhardness tests were performed at a variety of locations. A summary of the microhardness for cladding, FCCI layers, and fuel is given in Table 3. A reference hardness for unirradiated HT-9 cladding is $\mathrm{H}_{\mathrm{v}}=295 .{ }^{35}$ Hardness values for cladding below this value may be indicative of the elevated temperatures that the cladding experienced in these irradiation tests. Radiation should harden the cladding at a high enough dpa, but no dpa data are available for the cladding in these experiments to compare against literature. When present in metallic fuel, the FCCI zone is harder than the other fuel components. The oxide FCCI layer is highly variable due partially to extensive porosity in this layer. The hardness in the fuel in both the oxides and the metallic samples is also highly variable. No clear radial trends were observed in the samples, although this is not surprising, considering the variety of samples examined in these experiments.

Table 3. Summary of microhardness testing from different rodlet cross sections.

\begin{tabular}{llll}
\hline Rodlet & Cladding & FCCI & Fuel \\
\hline AFC-2E R1 & $354.7 \pm$ & $470.0 \pm 55.0$ & $164.0 \pm 50.6$ \\
& 10.9 & & \\
AFC-2E R2 & $317.5 \pm$ & $552.4 \pm$ N/A & $218.6 \pm 94.9$ \\
& 54.2 & & \\
AFC-2E R3 & $416.6 \pm$ & $314.5 \pm 77.8$ & $217.7 \pm$ \\
& 4.9 & & 104.7 \\
AFC-2E R4 & $369.3 \pm$ & $383.3 \pm$ & $282.3 \pm$ \\
& 42.5 & 104.1 & 109.6 \\
\hline AFC-2E R5 & $399.1 \pm$ & $342.8 \pm 89.8$ & $203.7 \pm$ \\
& 24.5 & & 105.4 \\
\hline AFC-2E R6 & $379.9 \pm$ & $397.7 \pm 14.7$ & $149.7 \pm 71.8$ \\
& 24.2 & & \\
\hline
\end{tabular}

\subsection{Analytical Chemistry}

During rodlet sectioning to create the microscopy samples, additional samples were taken from near the fuel stack center and sent to the INL Analytical Laboratory (AL) for a variety of chemical and radiological analyses. The primary goal of the analysis is to ascertain the burnup of the sampled material. Gamma spectrometry analysis is also performed. Axial variations in burnup along a rodlet, if any exist, can typically be scaled by comparing quantitative gamma spectrometry results from the AL to semiquantitative results from PGS. Mass spectrometry analysis can also provide information on the destruction of actinides and minor actinides. Minor actinide destruction is an essential feature of transmutation fuel, but the quasi-fast neutron spectrum (that is really an epithermal neutron spectrum created by the Cd baskets used in this experiment) does not produce a minor actinide mix in the fuel that is representative of the minor actinide mix seen in actual fast reactor fuel like EBR-II. 
Burnup is calculated from the results of mass spectrometry examinations of dissolved fuel samples. Samples are placed in a heated acid solution until both the fuel alloy or compound and the cladding have dissolved. Care is taken to ensure complete dissolution of all constituents, which can take up to 24 hours to complete. The AFC-2E U-Pu-Zr and U-Pu-Zr+MA samples were dissolved in $9 \mathrm{M} \mathrm{HCl}$.

Original solutions are saved for archive and in case a reanalysis is necessary. Aliquots of the original dissolution are diluted and sent through different inductively coupled plasma mass spectrometry devices (ICP-MS). Samples are sent through an ICP-AES (atomic emission spectrometry) to determine the cladding and sodium weight of the sample. Samples are then sent through an ICP-MS to determine the isotopic composition of the major constituents and fission products. In many cases there are isobaric (same atomic number) interferences that prevent exact identification of isotopic species. In the fission product data, isobaric interferences were not considered significant to the conclusions of this study, so no additional separations were performed to clear these interferences. Multi-collector ICP-MS (MC-ICP-MS) was performed on aliquots to determine the isotopic composition of the actinides. Isobaric interferences were considered significant in the actinides. A chemical separation to remove the $\mathrm{Pu}$ from the solution was performed to get $\mathrm{Pu}$-specific isotopics by mass spectrometry. These results were then compared to alpha spectrometry analysis of the same solutions, which resulted in good agreement. The MC-ICP-MS results for both the original solution and the Pu separation produced isotope specific results for U-234, U-235, U236, U-238, Pu-238, Pu-239, Pu-240, Pu-241, Pu-242, Np-237, Am-241, and Cm-244. No attempt was made to separate Am and Cm. The combined mass of Am-242 and Cm-242 is known, as well as the combined mass of Am-243 and Cm-243. Higher mass minor actinides were not measured. The final results from AL are archived as AL reports (log numbers 98656 to 98663 for AFC-2E).

The determination of burnup was performed using the measured mass of a specific fission product in the fuel, the cumulative fission yield of that specific fission product, and the total mass of actinides present in the sample. This method is sometimes referred to as the "Fission Product Monitor-Residual Heavy Atom" technique. ${ }^{36,37}$ Ideally, the fission products used in the calculations should have a small neutron absorption cross section, a high cumulative fission yield, and a similar fission yield for that nuclear isobar between $\mathrm{U}$ and $\mathrm{Pu}$ fission. Chemically the fission product must also readily dissolve during the leaching process. This technique uses the following formula to calculate burnup (BU) based on a specific fission product detected in the ICP-MS spectrum. Burnup is calculated in \% fission per initial heavy metal atoms (FIMA), which is comparable to heavy metal depletion and atom \% burnup units used in other sources.

$$
B U=\frac{\left(N_{f p} / y_{f p}\right)}{\left(\left(N_{f p} / y_{f p}\right)+N_{A c t}\right)} \times 100
$$

Where $N_{f p}$ is number of atoms of a specific fission product $f p$ measured in the sample, $y_{f p}$ is the cumulative fission yield of fission product $f p$, and $N_{A c t}$ is the number of atoms of actinides in the sample. All fission yields were taken from ENDF/B-VII.1. ${ }^{38}$ In the AFC-2 tests, enough fission occurred in actinides other than U-235 that the burnup would be biased if only the U-235 cumulative fission yield was used in Equation 1. The $\mathrm{Kr}$ to $\mathrm{Xe}$ ratio found in the fission gas release exams was used to estimate the fraction of U-235 and Pu-239 fissions in the experiments, and no other fissile or fissionable isotopes (e.g., Am-241, Am-243m, U-238, or others) were considered. For the AFC-2 samples, 33\% of the fission was assumed to come from $\mathrm{Pu}-239$. Effective yields are created as a weighted average of the different fission product yields based on the relative amount of fission that occurred in different actinides over the course of the experiment. A benefit of this burnup technique is that it requires no a priori knowledge of the sample. All the factors in Equation 1 can be directly measured from mass spectrometry results, and no assumptions about the pre-irradiation state of the fuel or the size of the sampled material need to be made. The described technique is largely similar to the more standardized Nd-148 burnup technique (ASTM E321). However, ASTM E321 requires a difficult Nd separation to remove Sm-148 and a correction to account for neutron 
absorption in Nd-148 that is only valid for thermal spectrum systems. Historically the Fission Product Monitor-Residual Heavy Atom" technique has performed quite well in the evaluation of EBR-II fuel.

There are six isotopes that work reliably for the ICP-MS technique in the AFC-2E fuel: La-139, Ce-140, Ce-142, Pr-141, Nd-145, and Nd-146. It should be noted that these same isotopes cannot be used in the case of simulated recycle (AFC-2A and AFC-2B) where fuel begins irradiation with mass percent levels of various rare earths. These isotopes occur on the higher atomic number peak of the bimodal fission product distribution. They are all lanthanides that will readily dissolve in the selected acid. The differences between U-235 yield and Pu-239 yield are fairly small for these isotopes as well. All these isotopes are nonradioactive and have relatively small neutron absorption cross sections, with the exception of Nd-145. Because of its cross section, the number of Nd-145 and Nd-146 atoms in the samples and their respective yields are summed in the calculation of burnup. In this calculation, the burnup measurement for each sample of particles was found by taking the average of the individual isotope results from Equation 1 for La-139, Ce-140, Ce-142, Pr-141, and the Nd-145 + Nd-146 combined result. The uncertainty of all mass spectrometry values is no better than 5\%, and the derived burnup values are also considered no better than $5 \%$ relative uncertainty. The derived burnup values and the burnup from simulation for each rodlet are shown in Table 4 for AFC-2E. For AFC-2, the simulations over-predict the measured burnup by 29 to $37 \%$. The source of this bias is anticipated to be explored further in future reanalysis of the AFC-2 experiments.

Table 4. Burnup values for AFC-2E.

\begin{tabular}{lll}
\hline Rodlet & $\begin{array}{l}\text { Preliminary } \\
\text { Burnup } \\
\text { (\%FIMA) }\end{array}$ & Simulation[24] \\
\hline AFC-2E R1 & $8.90 \%$ & $11.46 \%$ \\
\hline AFC-2E R2 & $9.14 \%$ & $11.93 \%$ \\
\hline AFC-2E R3 & $9.86 \%$ & $12.60 \%$ \\
\hline AFC-2E R4 & $9.89 \%$ & $12.28 \%$ \\
\hline AFC-2E R5 & $9.83 \%$ & $12.52 \%$ \\
\hline AFC-2E R6 & $7.49 \%$ & $9.91 \%$ \\
\hline
\end{tabular}

\section{SUMMARY}

Baseline PIE has been completed on rodlets from AFC-2E. This includes visual exams, neutron radiography, gamma spectrometry, dimensional inspection, fission gas release evaluation, optical microscopy, microhardness evaluation, and chemical analysis. The results compiled in this report offer an overall evaluation of the performance of the tested fuel systems. Baseline PIE provides an engineering or macroscopic scale evaluation of fuel performance and prepares samples for a more detailed phenomenological study of observed performance. Advanced PIE techniques are desired to obtain microscopic elemental and structural information in the fuel, in the cladding, and in the interface, where the composition of the FCCI layer is of great interest.

Evaluation of the tests discussed here is difficult. The irradiation conditions of all these tests deviated from the designed conditions, and behavior observed in PIE cannot necessarily be attributed to poor 
irradiation conditions or poor fuel performance. Exceptions do exist. The validity of the AFC-2E irradiations was likely damaged by poor irradiation conditions. There are, however, still useful data to be gained by comparing the AFC-2E R1 and AFC-2E R6 fuel to data from the X447 assembly and historic PIE. These rodlets should provide additional data on the margin performance of ternary fuels in fast reactors. 


\section{REFERENCES}

1. U.S. Department of Energy Office of Nuclear Science and Technology, Report to Congress on the Advanced Fuel Cycle Initiative: The Future Path for Advanced Spent Fuel Treatment and Transmutation Research, January 2003.

2. INL/EXT-10-18954, "FCRD Advanced Fuels Campaign Execution Plan, FCRD-FUEL-2011000105," Rev. 3, June 2013.

3. INL/EXT-05-00785, "AFC-1 Transmutation Fuels Post-Irradiation Hot Cell Examination 4 to 8 at.\% Final Report,” Rev. 1, B.A. Hilton, D.L. Porter, S.L. Hayes, 2006.

4. INL/EXT-06-11707, "Irradiation of Metallic Fuels with Rare Earth Additions for Actinide Transmutation in the Advanced Test Reactor Experiment Description for AFC-2A and AFC-2B," Rev. 1, S.L. Hayes, 2006.

5. G.L. Hofman, L.C. Walters, and T.H. Bauer, "Metallic fast reactor fuels," Progress in Nuclear Energy, Vol. 31, Nos. 1-2, 1997, pp. 83-110, ISSN 0149-1970, http://dx.doi.org/10.1016/01491970(96)00005-4.

6. G.L. Hofman, S.L. Hayes, M.C. Petri, "Temperature gradient driven constituent redistribution in U • Zr alloys," Journal of Nuclear Materials, Vol. 227, No. 3, January 1996, pp. 277-286, ISSN $0022-$ 3115, http://dx.doi.org/10.1016/0022-3115(95)00129-8.

7. Douglas C. Crawford, Douglas L. Porter, Steven L. Hayes, "Fuels for sodium-cooled fast reactors: US perspective," Journal of Nuclear Materials, Vol. 371, Nos. 1-3, September 15, 2007, pp. 202 231, ISSN 0022-3115, http://dx.doi.org/10.1016/j.jnucmat.2007.05.010.

8. W.J. Carmack, D.L. Porter, Y.I. Chang, S.L. Hayes, M.K. Meyer, D.E. Burkes, C.B. Lee, T. Mizuno, F. Delage, J. Somers, "Metallic fuels for advanced reactors," Journal of Nuclear Materials, Vol. 392, No. 2, July 15, 2009, pp. 139-150, ISSN 0022-3115, http://dx.doi.org/10.1016/j.jnucmat.2009.03.007.

9. PLN-3773, "Postirradiation Examination Plan for AFC-2 Metallic and Oxide Fuels," Rev. 0, H.J.M. Chichester, 2011.

10. PLN-4371, "Post irradiation Examination Plan for AFC-OS Irradiation Experiments," J.M. Harp, 2014

11. AFC-2E Report

12. "AFC-2E Experiment As-Built Data Package," INL internal document, INL RD-General Projects, https://edms/pls/edms/toto.dmx 3?f doc=2989730 (INL only).

13. PLN-2992, "Irradiation of AFC-2E Metallic Fuels for Actinide Transmutation in the ATR," Rev. 0, H.J.M. Chichester, 2009.

14. ECAR-622, "Cycle 145A Physics Evaluation of the AFC-2 Experiment in the East Flux Trap," Rev. 0, J.R. Mitchell and G.S. Chang, 2009.

15. ECAR-825, "Cycle 145B Physics Evaluation of the AFC-2 Experiment In The East Flux Trap," Rev. 0, J.R. Mitchell and G.S. Chang, 2009.

16. ECAR-893, "Cycle 146A Physics Evaluation of the AFC-2 Experiment in the East Flux Trap," Rev. 0, J.R. Mitchell and G.S. Chang, 2009.

17. ECAR-983, "Cycle 146B Physics Evaluation of the AFC-2 Experiment in the East Flux Trap," Rev. 0, J.R. Mitchell and G.S. Chang, 2010.

18. ECAR-1062, "Cycle 147A Physics Evaluation of the AFC-2 Experiment in the East Flux Trap," Rev. 0, J.R. Mitchell and G.S. Chang, 2010.

19. ECAR-1177, "Cycle 148A Physics Evaluation of the AFC-2 Experiment in the East Flux Trap," Rev. 0, J.R. Mitchell and G.S. Chang, 2010.

20. ECAR-1261, "Cycle 148B Physics Evaluation of the AFC-2 Experiment in the East Flux Trap," Rev. 0, J.R. Mitchell and G.S. Chang, 2010.

21. ECAR-1418, "Cycle 149A Physics Evaluation of the AFC-2 Experiment in the East Flux Trap," Rev. 0, J.R. Mitchell and G.S. Chang, 2011. 
22. ECAR-1551, "Cycle 149B Physics Evaluation of the AFC-2 Experiment in the East Flux Trap," Rev. 0, J.R. Mitchell and G.S. Chang, 2011.

23. ECAR-1658, "Cycle 150B Physics Evaluation of the AFC-2 Experiment in the East Flux Trap," Rev. 0, J.R. Mitchell and G.S. Chang, 2011.

24. ECAR-1762, "Cycle 150B As-Run Physics Evaluation of the AFC-2 Experiment in the East Flux Trap," Rev. 0, J.R. Mitchell and G.S. Chang, 2012.

25. ECAR-1514, "Physics Analysis for the AFC-3 Series Tests Specimens Designated for Insertion during Cycle 150-B into ATR Positions A-10 and A-11," Rev. 1, C.R. Glass and G.S. Chang, 2011.

26. ECAR-1677, "ATR Cycle 150B Projected Physics Evaluations for the AFC-3A and -3B Experiments in the A-1 0 and A-11 Positions," Rev. 0, M.A. Lillo, C.R. Glass, and G.S. Chang, 2011.

27. ECAR-1816, "ATR Cycle 151A As-run and 151B Projected Physics Evaluations for the AFC-3A and -3B Experiments in the A-10 and A-11 Positions," Rev. 0, C.R. Glass and G.S. Chang, 2012.

28. ECAR-2128, "ATR Cycle 151B As-run Physics Evaluations for the AFC-3A and -3B Experiments in the A-10 and A-11 Positions," Rev. 0, C.R. Glass and G.S. Chang, 2012.

29. TID-26711-P1, "Fundamental Aspects of Nuclear Reactor Fuel Elements," Energy Research and Development Administration (ERDA) Technical Document, D.R. Olander, 1976.

30. H.J.M. Chichester, D.L. Porter, and B.A. Hilton, Postirradiation Examination of AFC-1D, $1 \mathrm{G}, 1 \mathrm{H}$, and 2A Experiments, INL/LTD-11-23242, 2011.

31. H.J.M. Chichester, D.L. Porter, "Postirradiation Examination of AFC-2B and AFC-2C Experiments," INL/LTD-12-26154, Idaho National Laboratory, 2012.

32. D.D. Keiser Jr., "Metal Fuel-Cladding Interaction," Comprehensive Nuclear Materials, ed. Rudy J.M. Konings, Elsevier, Oxford, 2012, pp. 423-441, ISBN 9780080560335 , http://dx.doi.org/10.1016/B978-0-08-056033-5.00067-7.

33. B. R. Westphal,HFEF, ANL to B. G. Carlson, ANL, HFEF, "Metallographic Examination of Element DP-70 from S/A X447A," March 24, 1992, ANL Intra-Laboratory Memo

34. ANL-NT-240, "Fuel-Cladding Interaction Layers in Irradiated U-Zr and U-Pu-Zr Fuel Elements," Argonne National Laboratory, D.D. Keiser, 2006.

35. Thak Sang Byun, Jong-Hyuk Baek, Osman Anderoglu, Stuart A. Maloy, and Mychailo B. Toloczko, "Thermal annealing recovery of fracture toughness in HT9 steel after irradiation to high doses," Journal of Nuclear Materials, Vol. 449, Nos. 1-3, June 2014, pp. 263-272, ISSN 0022-3115, http://dx.doi.org/10.1016/j.jnucmat.2013.07.064.

36. TID 26209, "Burnup Determination for Fast Reactor Fuels: A Review and Status of the Nuclear Data and Analytical Chemistry Methodology Requirements," NTIS Report, Maeck, W.J., Larsen, R.P., and Rein, J.E., 1973.

37. J.M. Harp, P.A. Demkowicz, P.L. Winston, J.W. Sterbentz, "An analysis of nuclear fuel burnup in the AGR-1 TRISO fuel experiment using gamma spectrometry, mass spectrometry, and computational simulation techniques," Nuclear Engineering and Design, Vol. 278, pp. 395-405, 2014, http://dx.doi.org/10.1016/j.nucengdes.2014.07.041.

38. M.B. Chadwick, et al. "ENDF/B-VII. 1 nuclear data for science and technology: cross sections, covariances, fission product yields and decay data." Nuclear Data Sheets, Vol. 112, No. 12, pp. 2887-2996, 2011. 


\section{Appendix A: Rodlet Visual Exams}

AFC-2E

AFC-2E R1

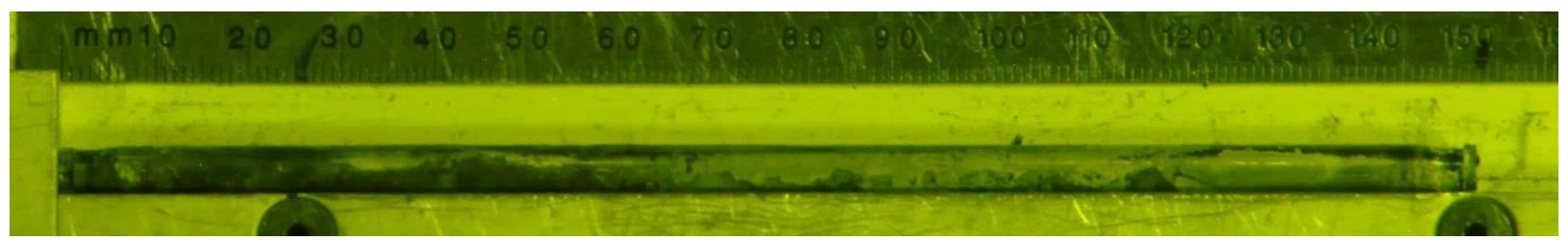

AFC-2E R2

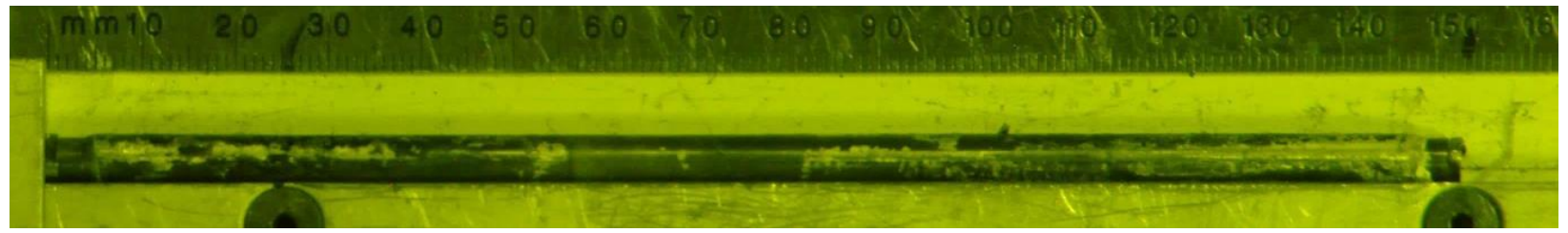

AFC-2E R3

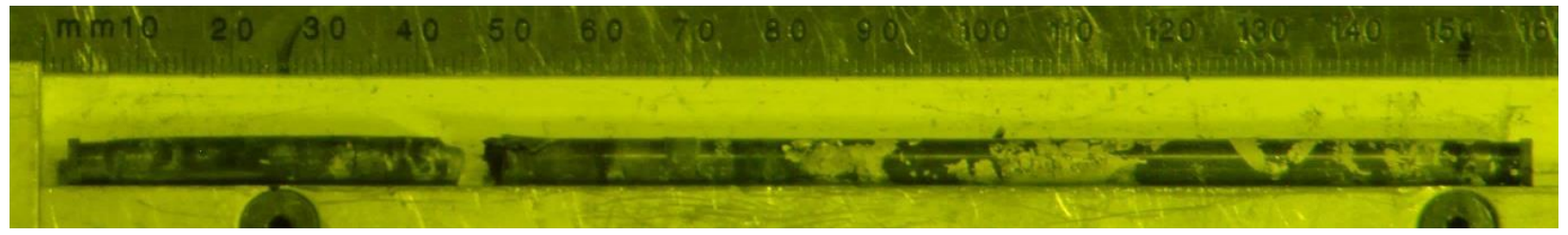

AFC-2E R4

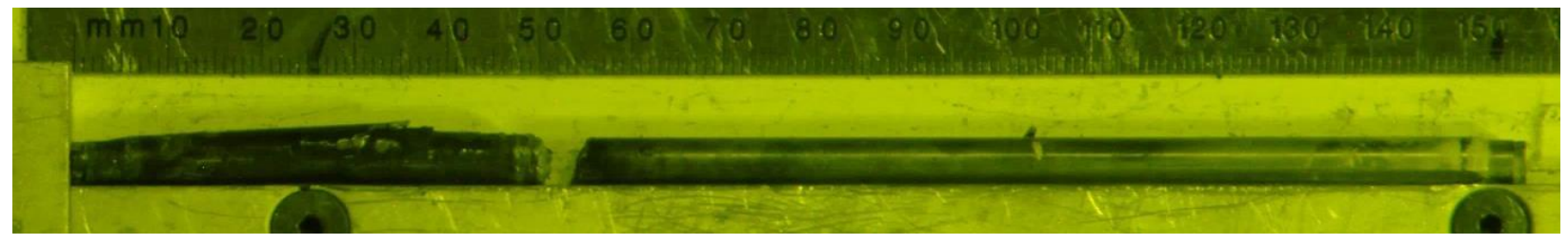

AFC-2E R5

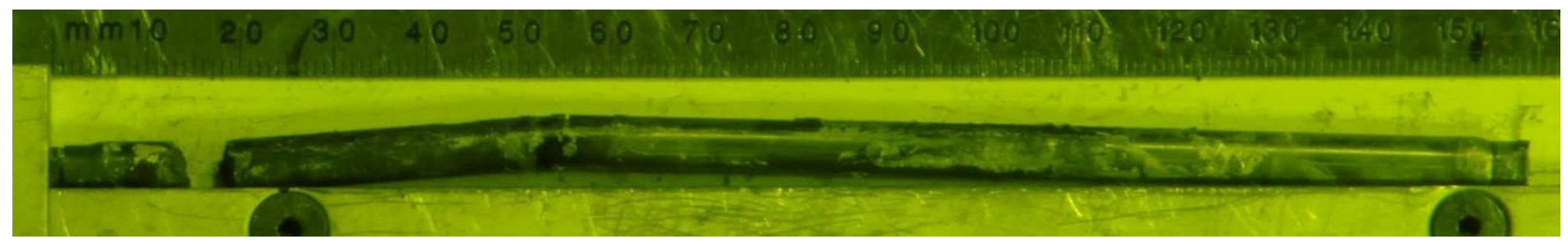

AFC-2E R6

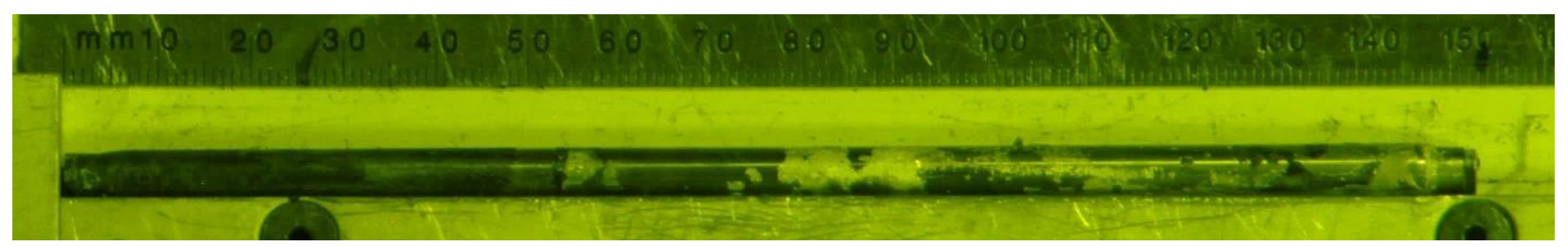


AFC-2E after Cleaning

AFC-2E R1

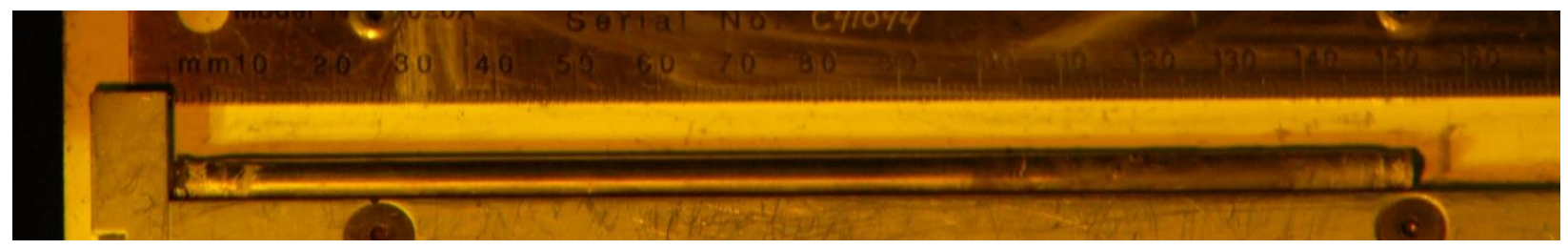

AFC-2E R2

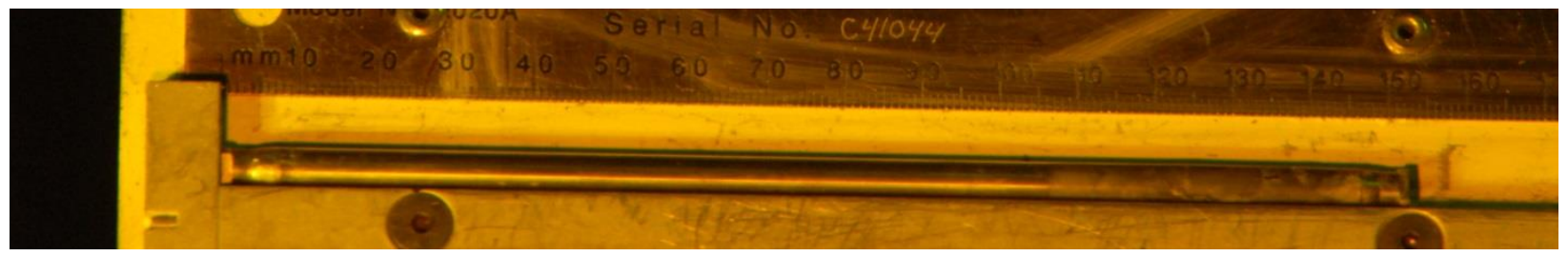

AFC-2E R6

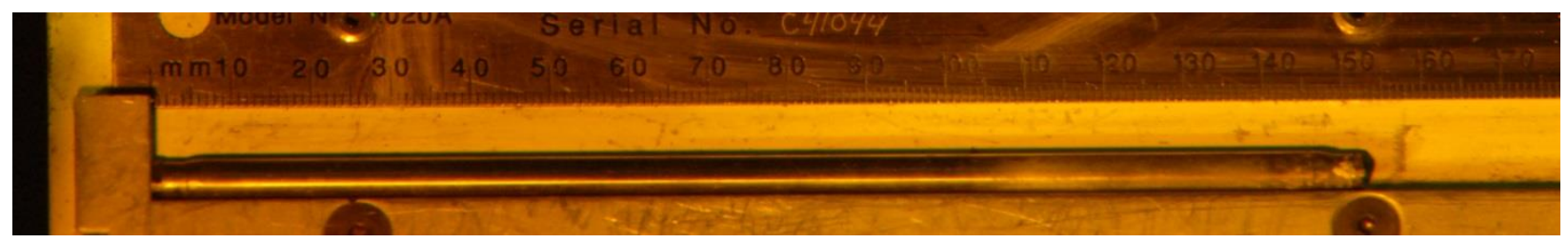




\section{Appendix B: Gamma Spectrometry of Rodlets}

AFC-2E

AFC-2E R1

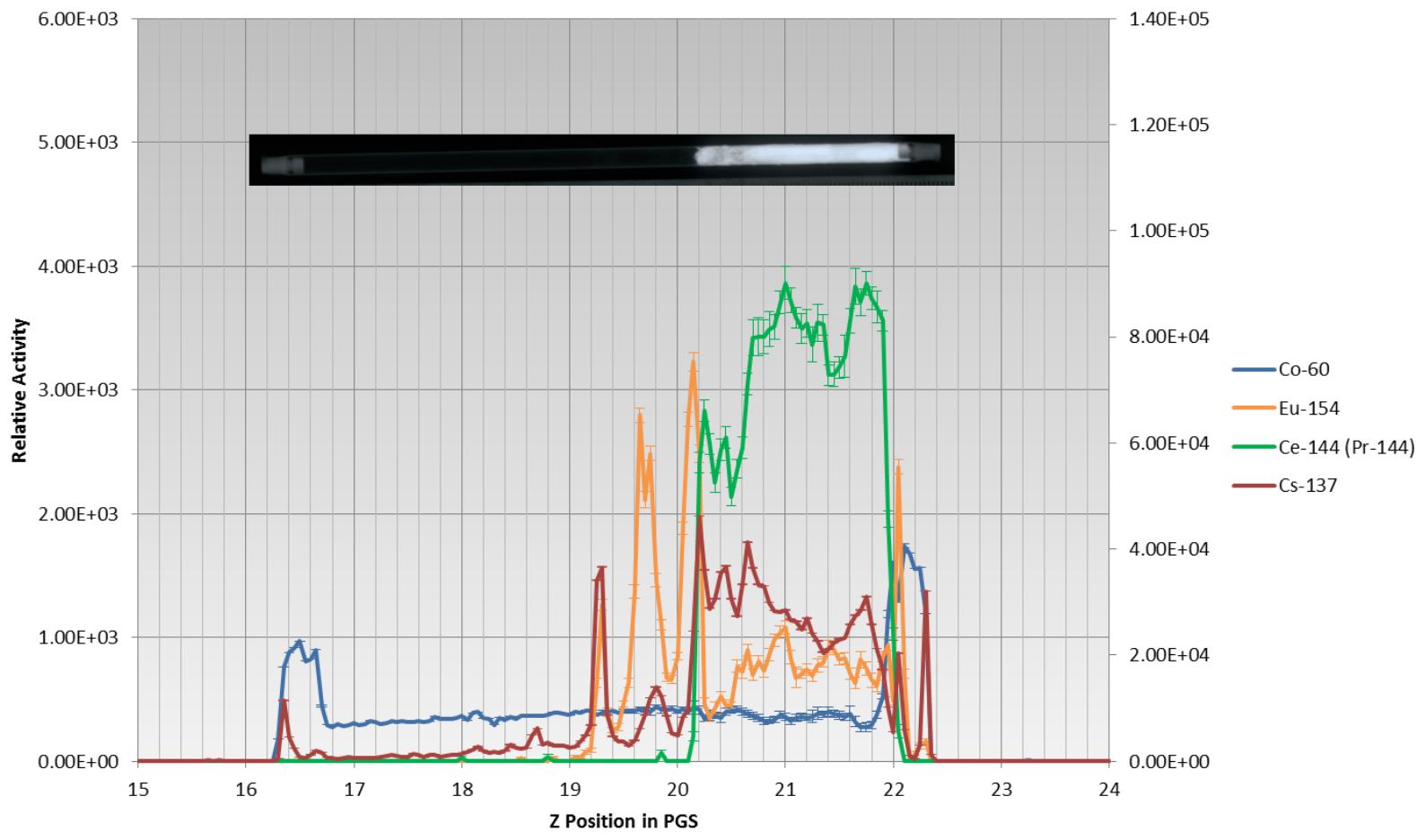

AFC-2E R2

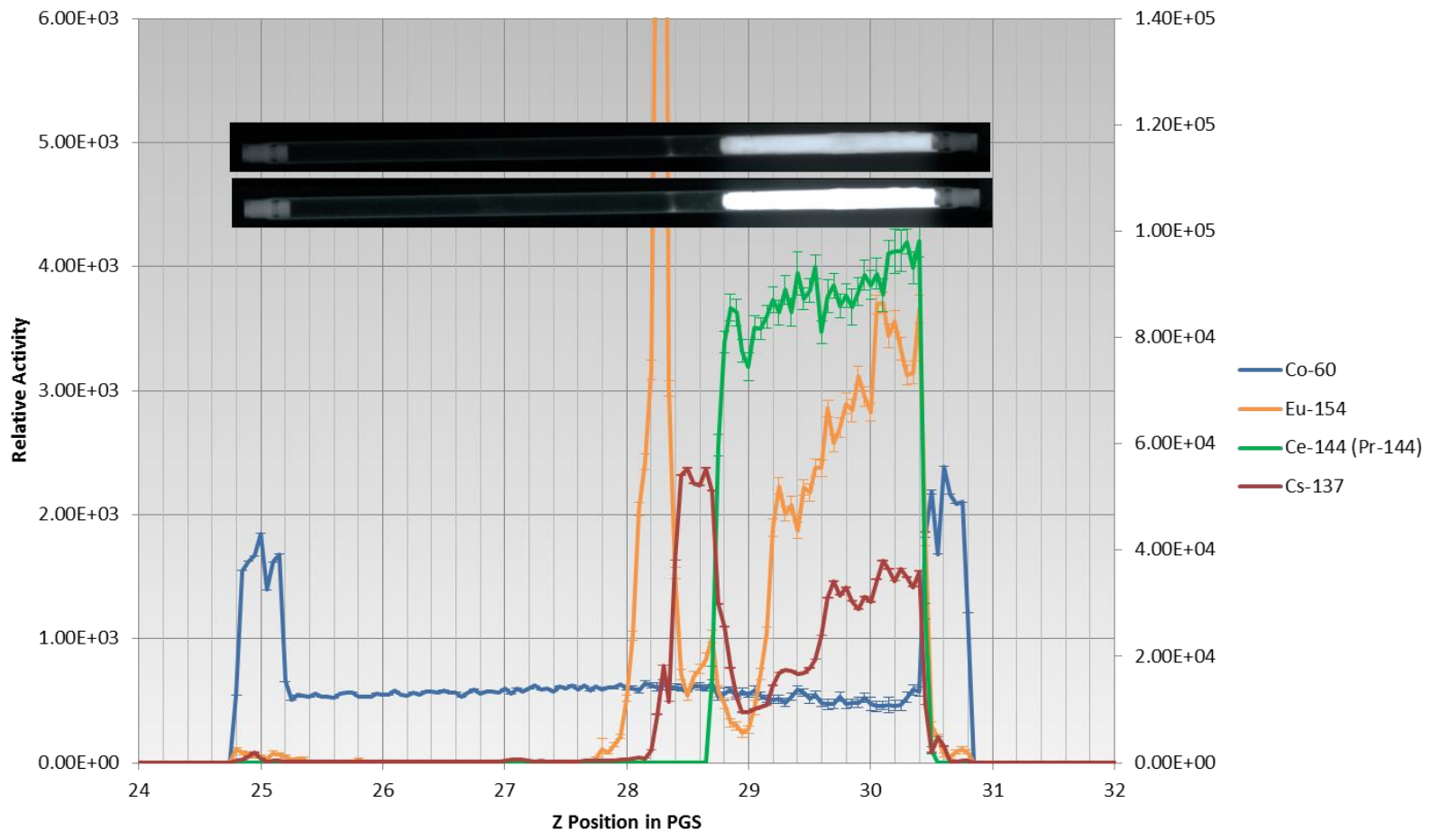




\section{AFC-2E R3}

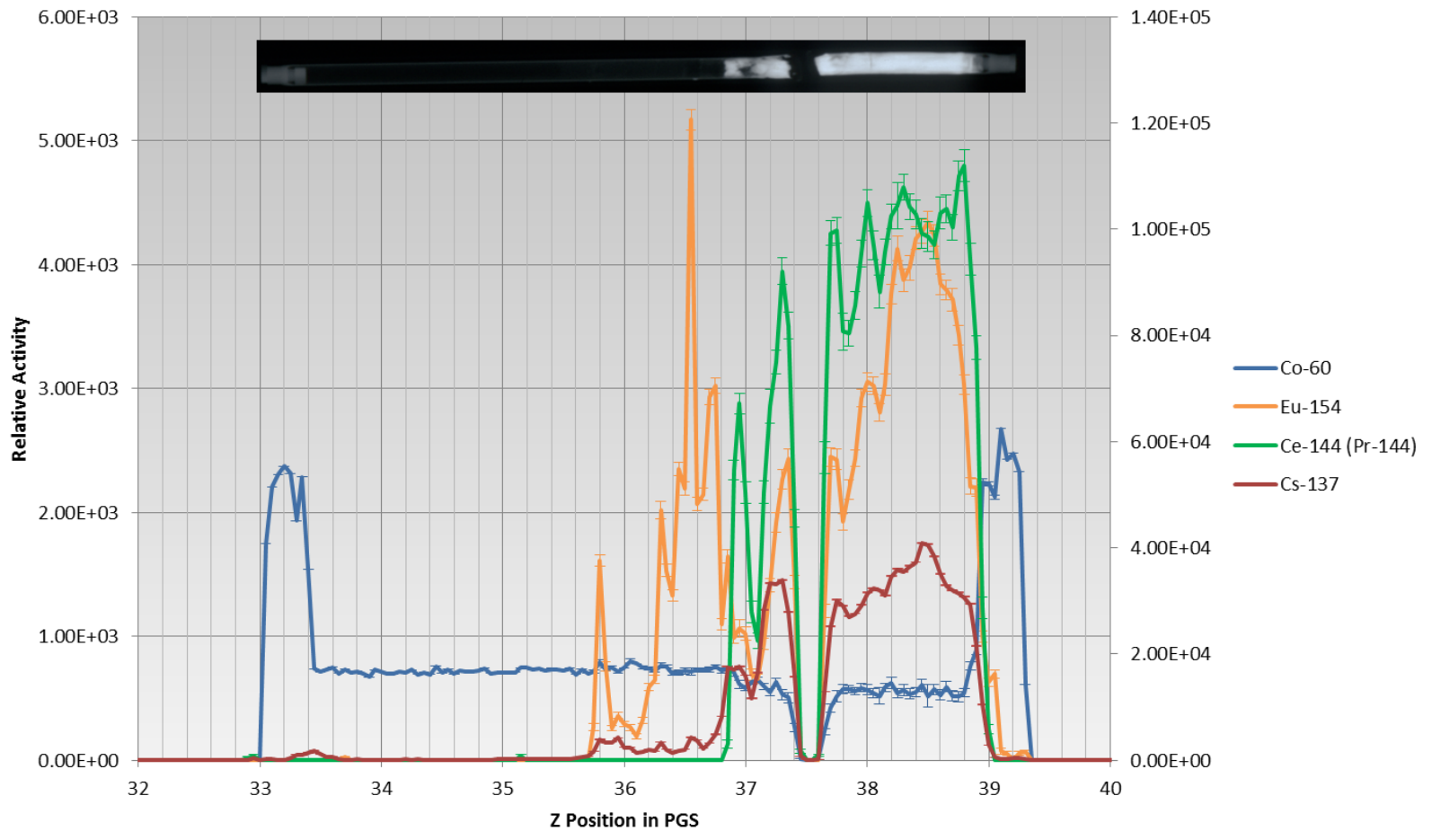

\section{AFC-2E R4}

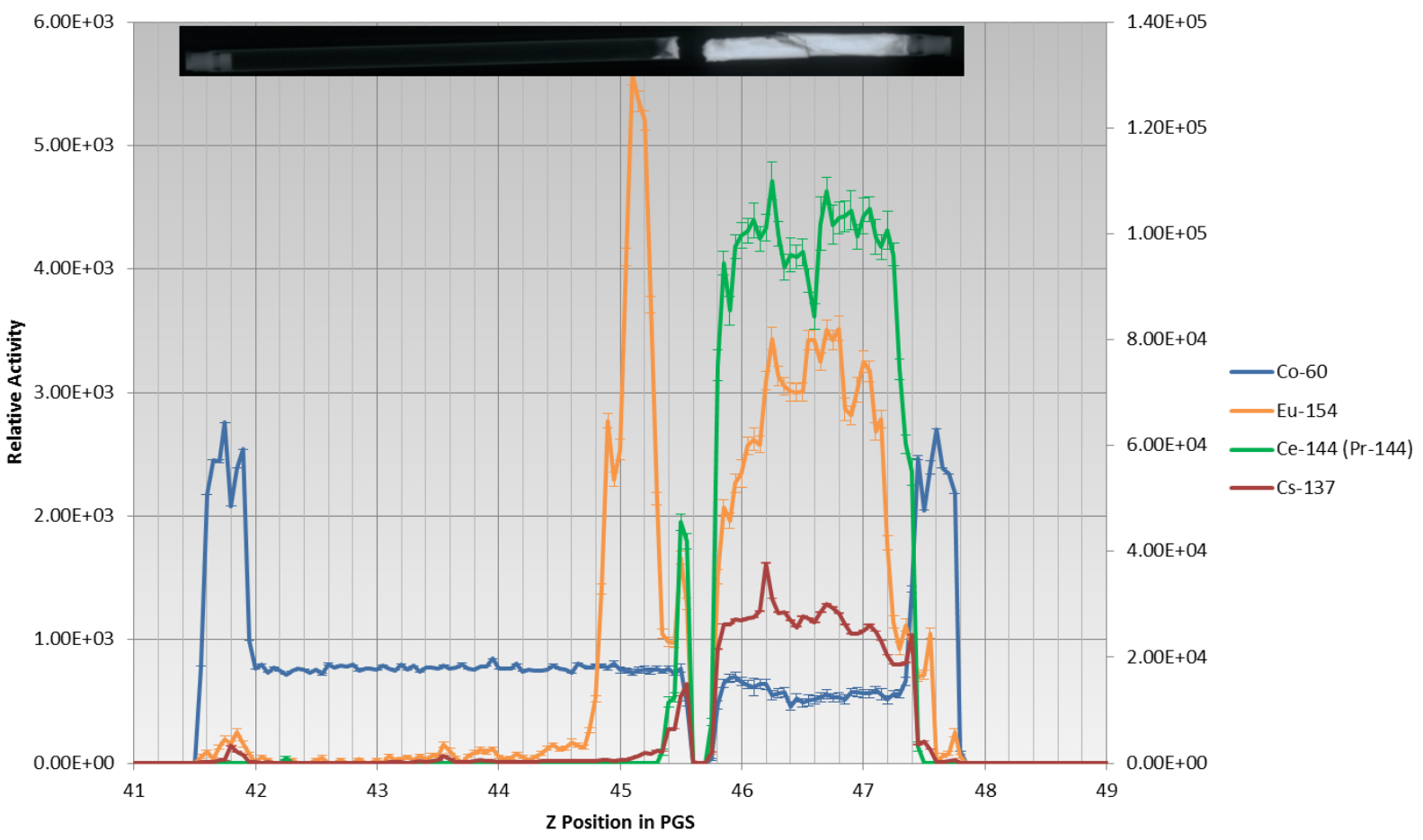




\section{AFC-2E R5}

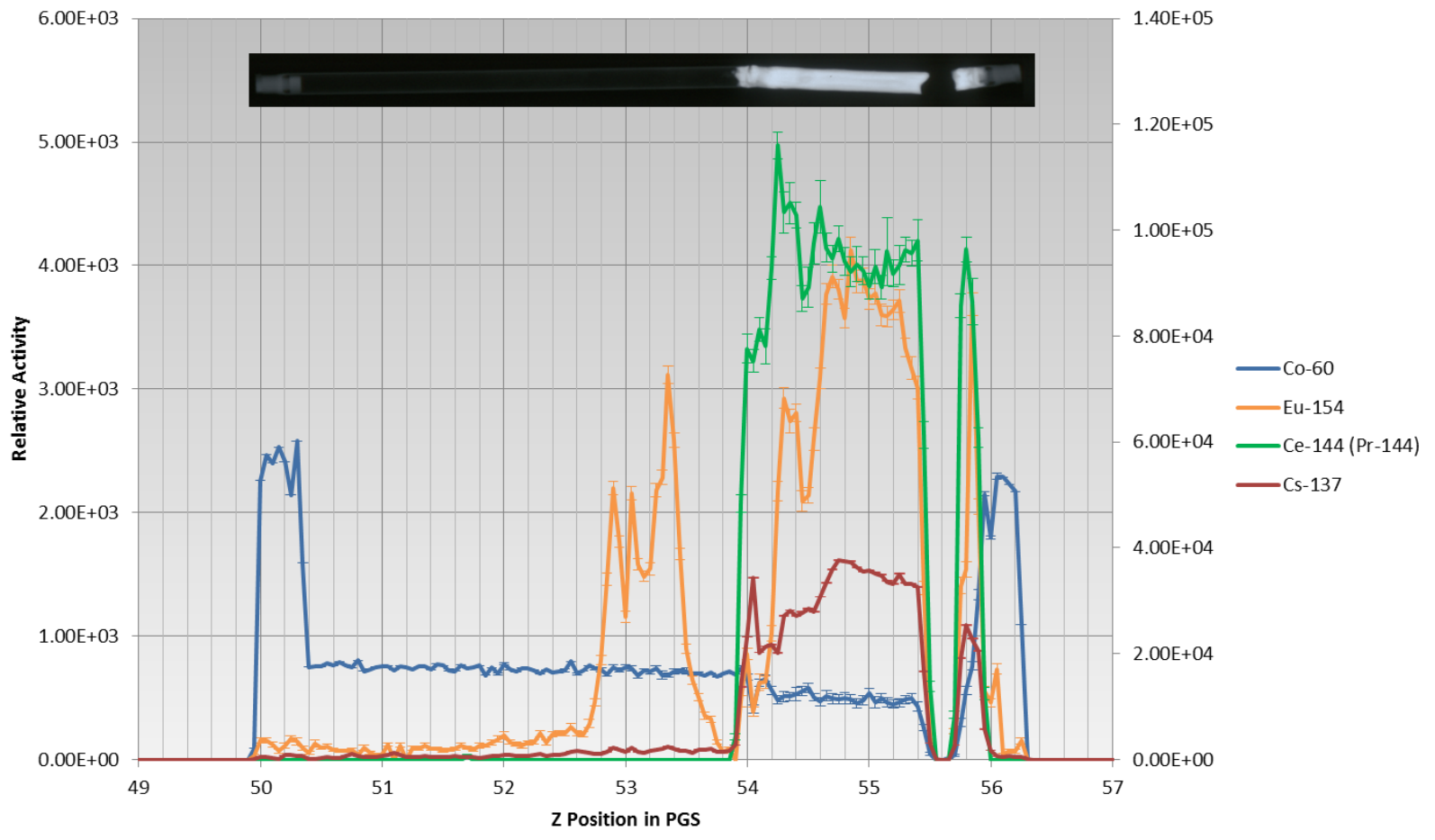

\section{AFC-2E R6}

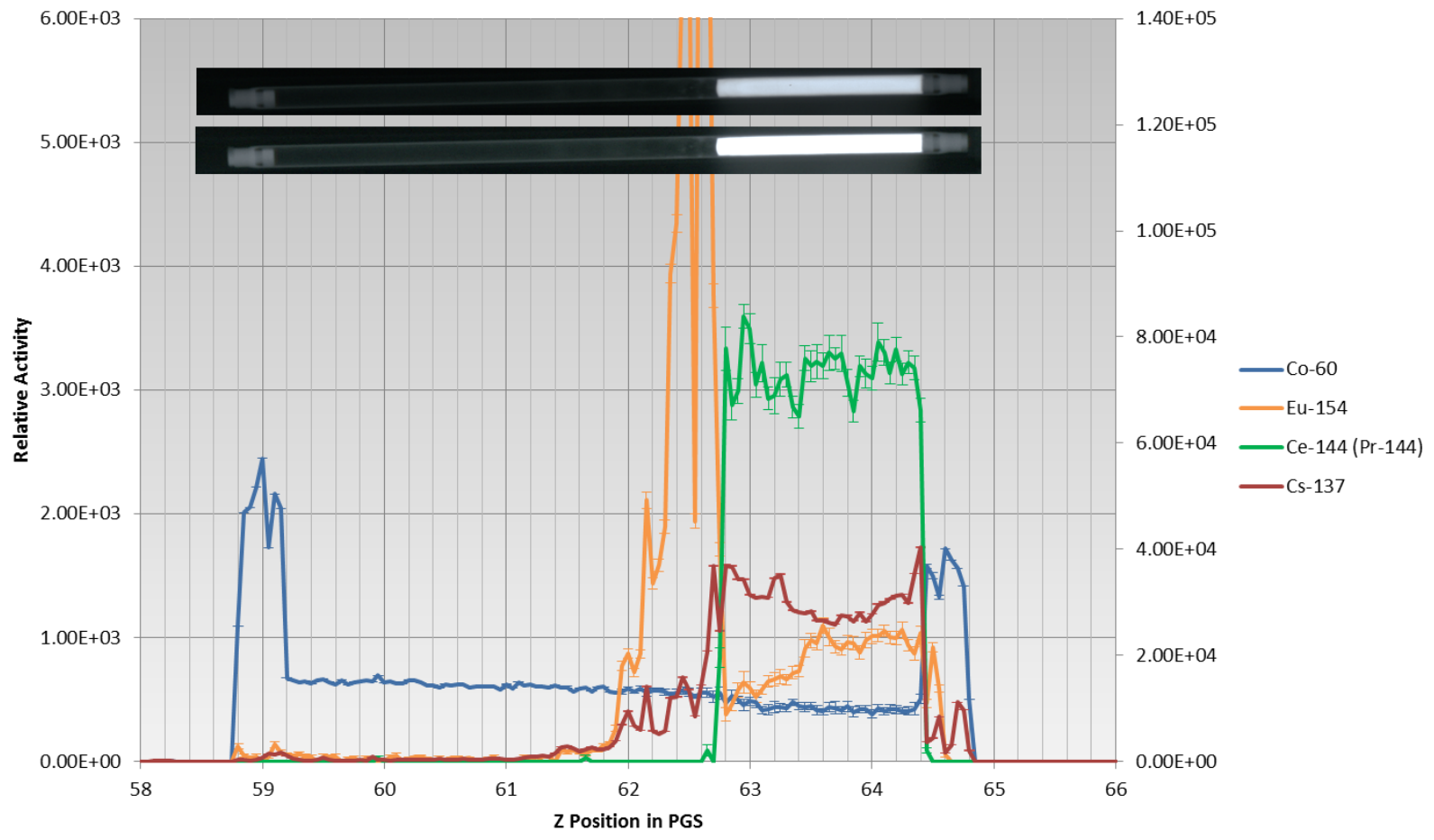

